2010

\title{
Student Perceptions of Interactive Whiteboards and Effects on Academic Achievement in a Fourth Grade Language Arts Classroom
}

Everett B. Burke

Cedarville University

Follow this and additional works at: http://digitalcommons.cedarville.edu/education_theses

Part of the Elementary and Middle and Secondary Education Administration Commons

\section{Recommended Citation}

Burke, Everett B., "Student Perceptions of Interactive Whiteboards and Effects on Academic Achievement in a Fourth Grade Language Arts Classroom" (2010). Master of Education Research Theses. 45.

http://digitalcommons.cedarville.edu/education_theses/45 
STUDENT PERCEPTIONS OF INTERACTIVE WHITEBOARDS AND EFFECTS ON

ACADEMIC ACHIEVEMENT

IN A FOURTH GRADE LANGUAGE ARTS CLASSROOM

\begin{abstract}
A thesis submitted in partial fulfillment of the requirements for the degree of

Masters of Education
\end{abstract}

By

EVERETT BEN BURKE

B.S. Elementary Education, Olivet Nazarene University, 2002

2010

Cedarville University 
Cedarville University

School of Graduate Studies

July 29,2010

I HEREBY RECOMMEND THAT THE THESIS PREPARED UNDER MY SUPERVISION BY Everett B

Burke ENTITLED, "Student Perceptions of Interactive Whiteboards and Effects on Academic Achievement in a Fourth Grade Language Arts Classroom," BE ACCEPTED IN PARTIAL FUFILLMENT OF THE REQUIREMENTS FOR THE DEGREE OF Master of Education.

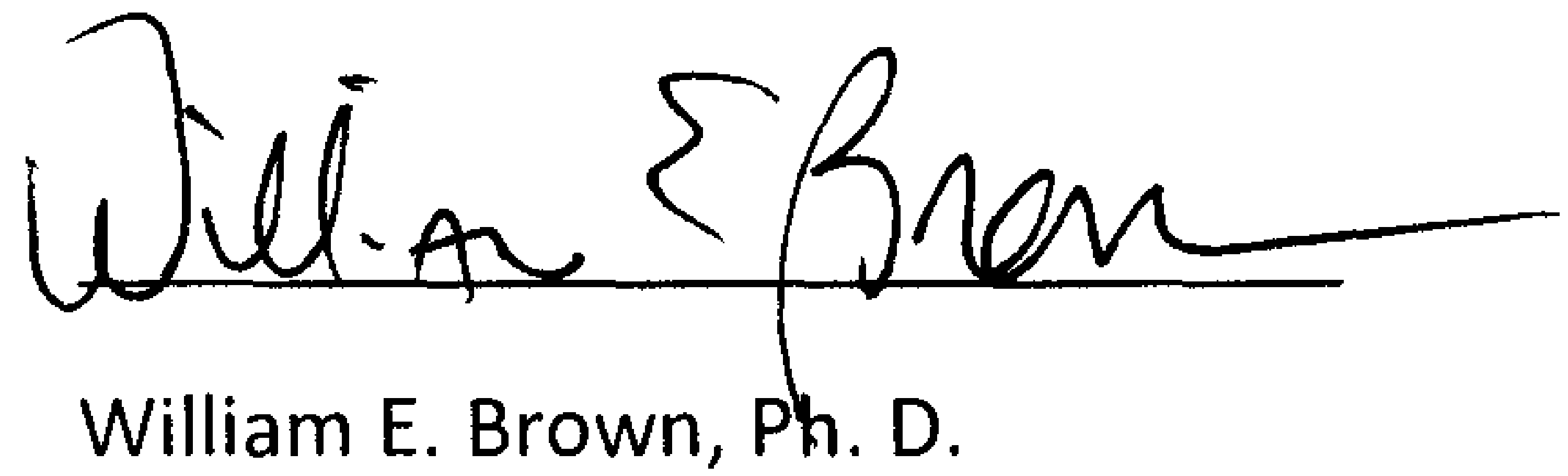

President

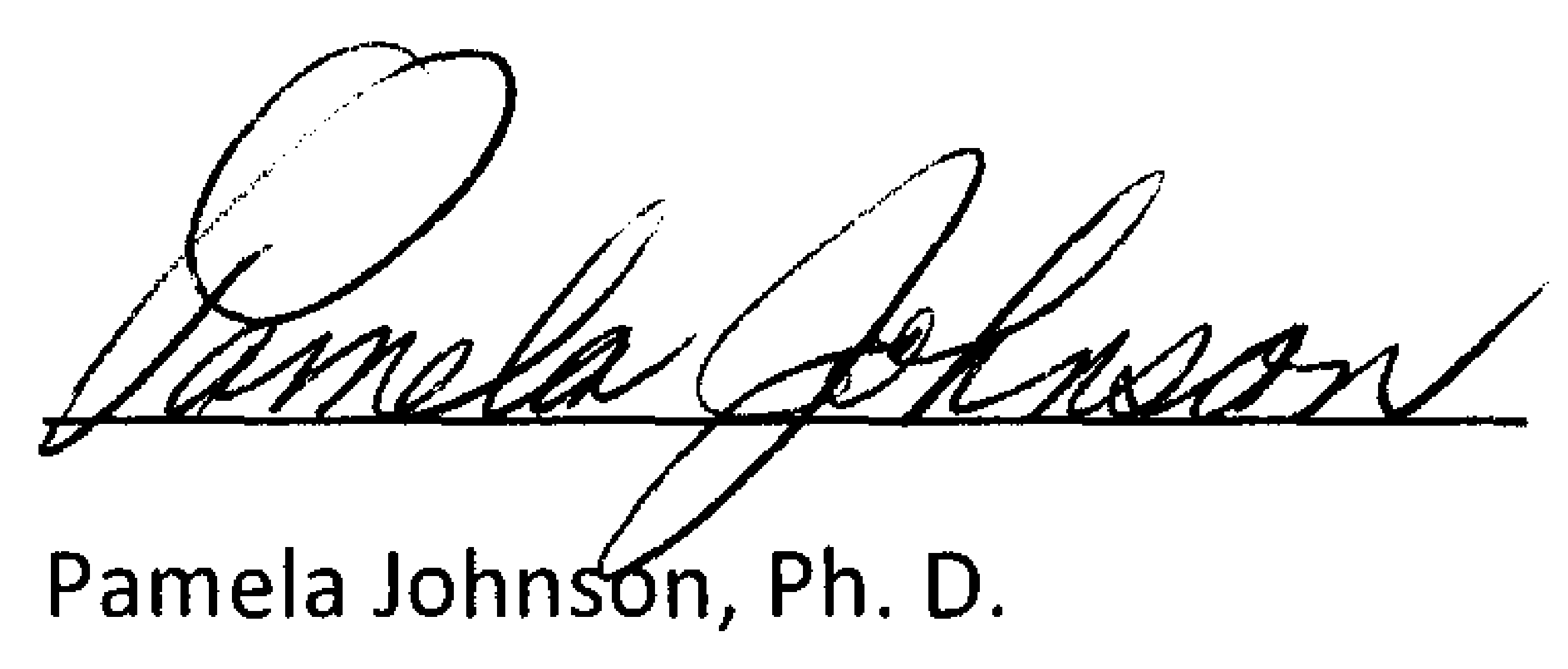

Dean of Social Sciences

And Human Performance

Hemettry L Lector Timothy L. Keaton Ph. D.

Education Department

Thesis Advisor

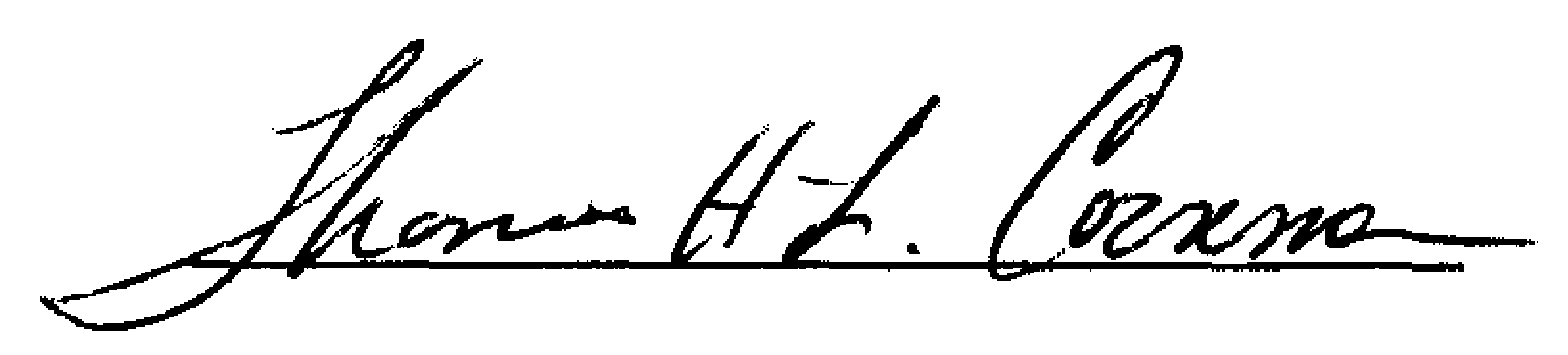

Thomas H.L. Conman, Ph.D.

Academic Vice President

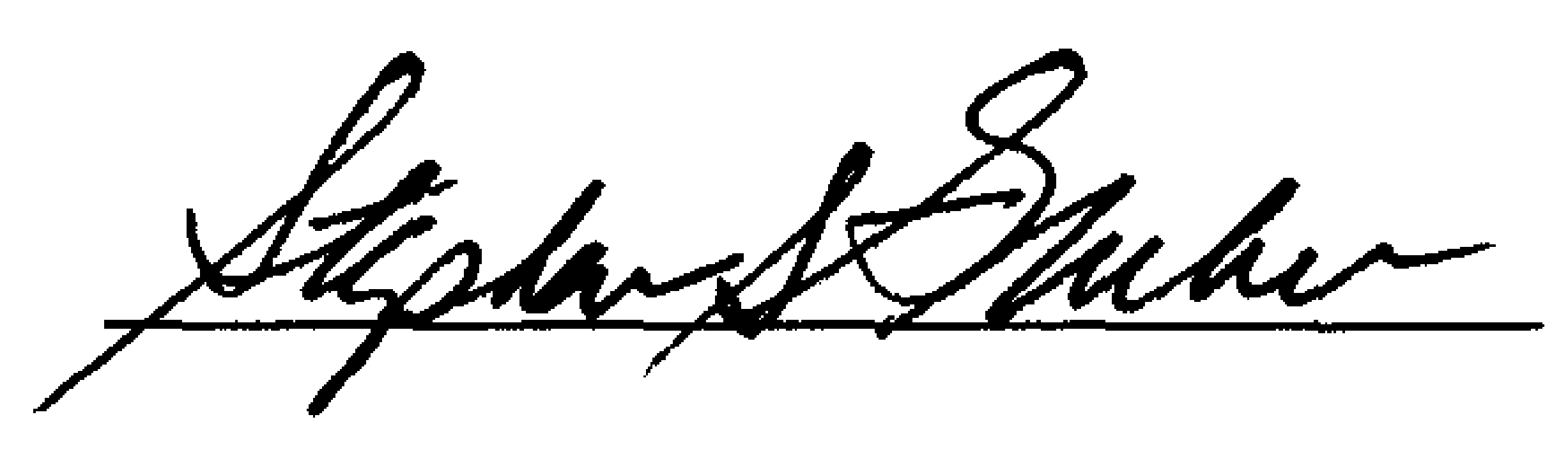

Stephen S. Gruber, Ed.D.

Coordinator, Master of

Education Degree Program 


\begin{abstract}
Burke, Everett B. M.Ed., Education Department, Cedarville University, 2010. Student perceptions of interactive whiteboards and effects on academic achievement in a fourth grade language arts classroom.
\end{abstract}

This is a mixed study on technology in the educational setting about student perceptions of interactive whiteboards (IWB) and if there are measurable effects of the IWB's on student performance. This was a within subject design with a counterbalancing of order study set in a fourth grade classroom and lasted for a period of four weeks. In keeping with a true counterbalance study one group was exposed to instruction with heavy emphasis on the use of an interactive whiteboard. Concurrently another group was exposed to instruction of the same material through more traditional technology including an overhead projector, dry-erase board, and T.V. monitor. After a predetermined amount of time the group's roles were reversed to create measurable data. Qualitative data was gathered through a series of interviews that focused solely on the thirty-four participants' perceptions. Such perceptions that were focused on were benefits, limitations, and suggestions for improvement. The quantitative data was gathered in the form of short cycled assessments of material covered during the study. 


\section{TABLE OF CONTENTS}

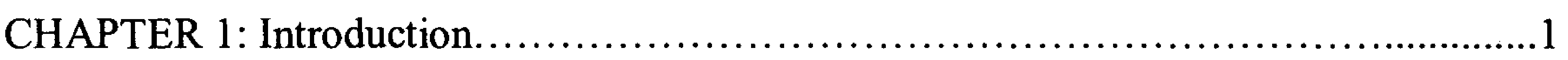

Definition of Terms............................................................

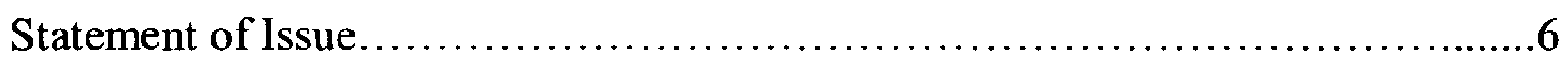

Scope of the Study and Delimitations......................................6

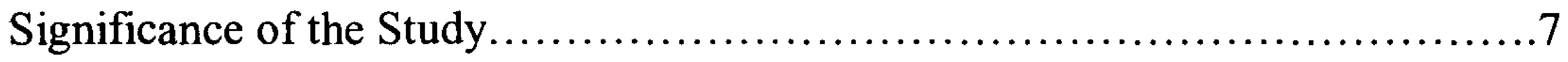

Methods of Procedure ......................................................... 9

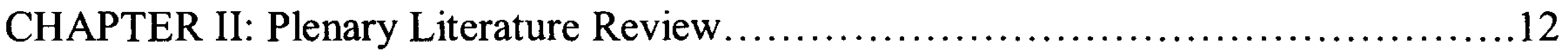

Technology and Learning Theories........................................12

Summary of Relevant Literature ..........................................14

Technology Implementation..............................................

Benefits of Educational technology .....................................15

Limitations and Barriers of Educational Technology ........................17

Types of Information and Communications Technology .....................20

Student perceptions of technology......................................21

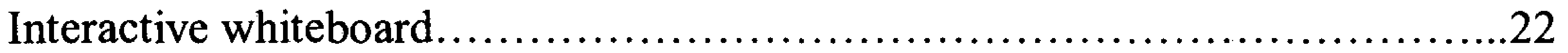

Specific uses of Interactive Whiteboards...............................23

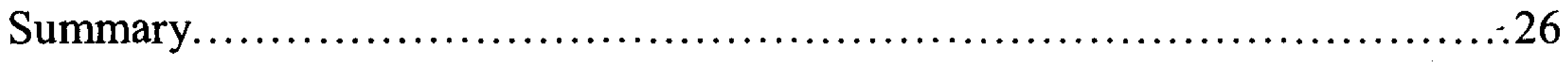

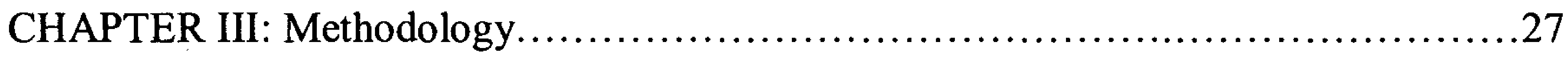

Rationale for the Method..................................................33

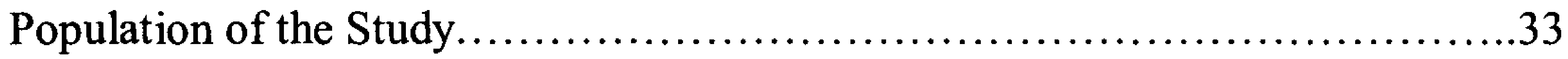

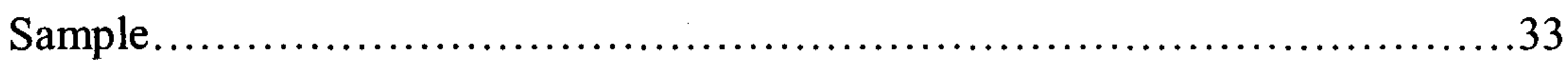

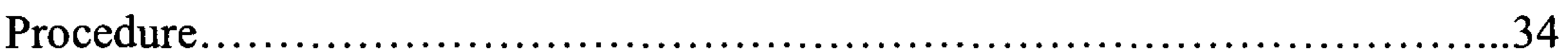


CHAPTER IV: Qualitative and Quantitative Analysis.

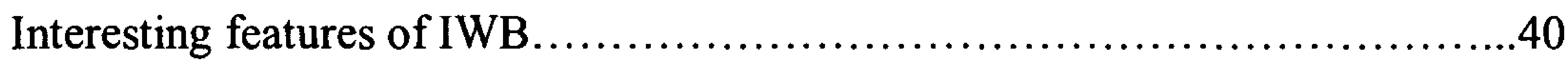

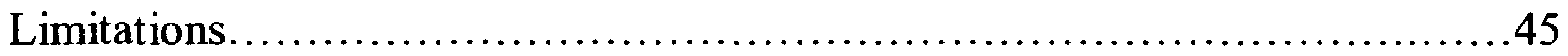

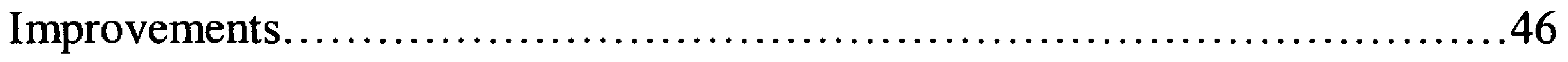

Quantitative Analysis................................................47

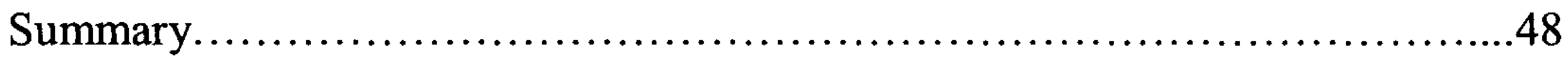

CHAPTER V: Discussion and Implications ......................................50

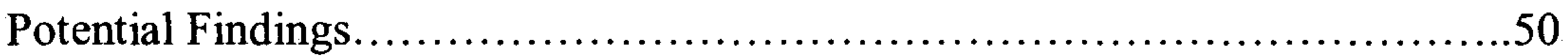

Quantitative Analysis.................................................5

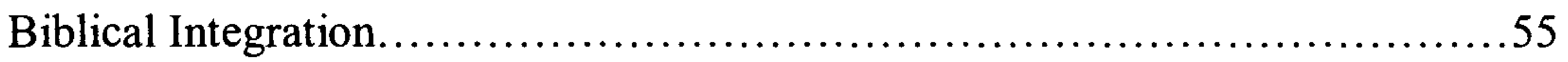

Relation of the results to Literature .......................................55

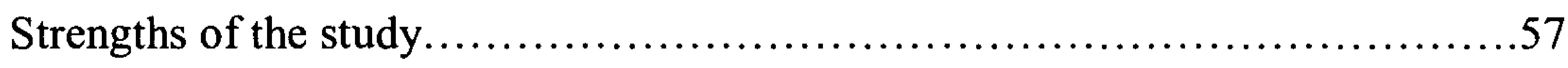

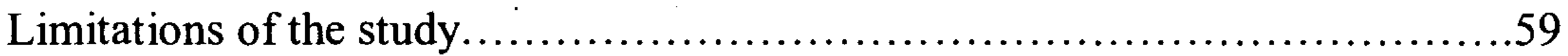

Suggestions for future Research......................................60

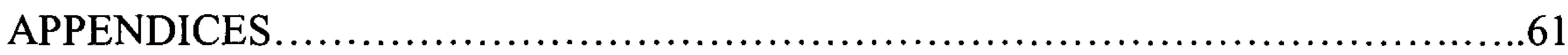

APPENDIX A: Interview Questions....................................61

APPENDIX B: Parental Consent Form...................................62

APPENDIX C: Sample Journal Entry ....................................63

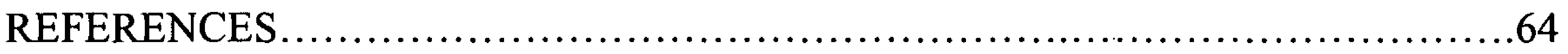




\section{Introduction}

Technology is changing the way the world works at a faster pace than ever. The world is connected at a touch of a button and the passing of thoughts and ideas have become almost instantaneous. Technology has become a part of our everyday lives and this has happened with little to no objection or controversy. Education is a field that is not impervious to the technological revolution. A computer is as prevalent in today's modern school as a wood stove was in the one room school houses of the past.

As computers have become common place in the classroom, their use is what has come into a focus of debate. Of course, teachers have used computers for administrative and organizational capacities for a while now, whether it is for such things as lunch counts, attendance, as well as the recording and storing of grades (NEA 2006). So the debate now is how we should use computers as an instructional instrument. Researchers, educators, technology companies, and the government all have unique points of view concerning the use of technology. Researchers both support and question the use of technology, while technology companies are quick to point out the advantages of using technology. The Federal Government generally supports the use of technologies in the classroom by funding thirty-five percent of all educational technology Honey (2001).

So with technology being at the heart of our society and putting a world of information at our finger tips what is there even to debate? Dede (1997) points out that people perceive multimedia- capable internet connections as magical devices, or "silver bullets" that will solve all the problems of the schools. Dede goes on to point out that people often compare technology to a fire; children just benefit by sitting near it. Also 
Dede goes on to point out the cost of technology, claiming that the use of technology will only raise the cost to educate.

We must now move to the rebuttal for technology. These proponents contend that learning happens best when four factors are present, all of which are magnified by the use of technology. Driscoll (2002) argues that technology makes learning active. Secondly, to learning is social, which is fostered by technology. Thirdly, learning is reflective, and finally technology provides a context in which kids that are raised in a technological world understand. Knowlton (2008) contends that using technology in schools improves student engagement, improves motivation and attendance, incorporates different learning styles, and improves review and retention, while also increasing teacher productivity.

A factor that increases the intensity of this debate is the ever increasing pressure to raise test scores. School districts are scrambling to put in place whatever it takes to reach their ever increasing goals. John Bailey, the technology director under President George W. Bush, said it would be nearly impossible for schools to meet the federal No Child Left Behind Act requirements without technology (as cited in Vail, 2003). However, as (Driscoll 2002) points out, technology by itself does not guarantee the existence of learning. In research done by White, Ringstaff, \& Kelley, (2002) point out that technology must be used effectively in order to positively impact learning.

So how is technology being used as an instructional instrument in classrooms around the country? According to Lockard \& Abrams (2001), the bulk of the use of technology is in the form of instructional CD-ROMS, Internet, web quests, or distance learning or other types of computer based program. These technologies are classified into what have been dubbed information and communication technologies or (ICT). One 
of the most accepted software systems being used in schools is Microsoft office.

Microsoft office can be used with either a P.C. or with a Mac. Microsoft office contains Word which is a word processing program used to create typed documents such as letters, term papers, and teacher-created tests. Another aspect of Microsoft office is PowerPoint. PowerPoint is used to generate presentations. When combined with an Interactive whiteboard (IWB) PowerPoint can take advantage of spelling check, allowing the user to add, correct, make changes to the lessons, and finally use printout materials for student's personal use (Teach-nology.com 2007). PowerPoint gives the user the opportunity to incorporate visual and auditory aspects to a presentation. Visual aspects of PowerPoint, when combined with an interactive whiteboard (IWB), integrate pictures, texts, video clips, and have the capability to pause, circle, annotate and highlight (Branzburg 2006).

The adjustment of teaching styles is a major component that has to be considered when e-teaching. According to (Kent 2006) e-teaching is the use of IWB's and the use of ICT to improve the ability of the teacher. To integrate technology into teaching, Lee (2002), calls for a shift in the paradigm of teaching from teacher-centered into a learnercentered inquiry. In a teacher-centered classroom: the teacher talks, students listen, students work alone, teachers answer questions, and choose the topics to be learned. In a learner-centered classroom, the focus is on both the students and the teacher. Students interact with both the teacher and other students. Students also have choices of topics and often work in groups (Weimer, 2002). The shift in teaching styles is driven by technology.

Technical support is also a major obstacle to the full integration of technology. According to the (NEA, 2006), teachers are not prepared to integrate instructional 
software coupled with not receiving the technical support needed to maintain and update software. Additionally, teachers will require in-services to address technology concerns, as well as the need for a capable I.T. director. Furthermore Yanik and Porter (2008) reinforce these notions by stating two main reasons that teachers do not use technology, are being unfamiliar with programs, and the second being the lack of experience with knowing how to use technology to enhance and complement their teaching. The (NEA, 2006) points to insufficient and outdated equipment and software as being a hurdle to the integration of technology.

Regardless, technology is becoming more and more a fundamental part of education in America today. President Obama and Congress passed 650 million dollars as a part of a federal stimulus package for the Enhancing Education Through Technology (Miners, 2009). This money is to be spent on improving today's schools through the integration of technology.

\section{Definition of Terms}

E-Teaching - Any teaching that includes the use of an IWB or the use of any ICT to enhance the art of teaching (Kent, 2006).

Hardware-All of the metal and plastic components of a computer, the physical equipment that goes along with or is connected to a computer (Geisert \& Futrell, 2000).

Hyperlink- a hyperlink is a graphic or other piece of text in an Internet document that can connect readers to another webpage (Ellis-Christensen, 2009).

Information and Communications Technology (ICT)- Any technology that can store, retrieve, manipulate, transmit, or receive information, and then communicate information 
by electronic means, including tools such as computers, email, software, and Internet (Introduction- What is ICT, 2009).

Interactive Whiteboard (IWB)- Display board which connects to a computer and can be used as computer monitor to show text. The board is also interactive with the touch of a finger or a special pen, much like a mouse pad for a traditional computer. The board possesses multimedia capabilities such as displaying written text, graphics, and video which can be manipulated, and moved. (SMART Technologies, 2009)

Internet- This is a worldwide collection of networks that link together businesses, government, educational institutions, and individuals as part of the World Wide Web (WWW) and other communication functions such as e-mail (Shelly, G. B, Cashman, R. E., \& Gunter, G. A. (2004).

Liquid Crystal Display (LCD) Projector- JCD projector enables a digital image to be projected onto a large screen for multi-user viewing (Lockard \& Abrams, 2001).

Multimedia- multiple forms of media such as text, graphics, audio, animation, video, and data integrated together (tech-faq.com, 2009.)

PowerPoint- Software program from Microsoft used to create presentations electronically with text, graphics, movie clips, and to implant sound to slides. Often used with LCD projector to show presentations to a large group (Roblyer, 2006).

Software- The program or the manner in which computers manipulates information (Geisert \& Futrell, 2000).

Virtual field trips are a computer based simulation of an actual field trip Clark, Hosticka, Schriver, \& Bedell (2002). 
Web Quests- are inquiry-Oriented lesson format in which most or all information that learners work with come from the web (Dodge, 2007).

Statement of Issue

When teachers are introduced to something new, there is both excitement and concern. With the rise of technology in schools, both excitement and concern hold true. The excitement comes with technologies offering what seem to be unlimited possibilities. This in turn causes concern over the best ways to use new technologies. Shorr, (2006) wrote about the best practices for using an IWB and pointed out that teachers should ask their students what they like and dislike. The student perception of the IWB is needed for teachers to better understand how to use the technology to enhance their teaching Shorr (2006). While student perceptions do have value it must be combined with academic gain, to contribute in finding the best practices of IWBs. During this study I focused on those areas I currently teach which are fourth grade language arts and social studies. Scope of the Study and Delimitations

In this study, I collected data on students' perceptions of believed benefits and limitations of an IWB in a Language Arts and Social Studies classroom, while tracking academic gain. I used student journals and interviews to define students' perceptions of technology. As a part of this study, I also evaluated ways in which students believed the use of an IWB could be improved. The academic gain was tracked by the use of weekly short cycle assessments. However the teacher's perceptions of the IWB were not incorporated into this study. The students in this study were exposed to IWBs in other subject areas. However, student's perceptions in those other areas were not included as part of this study. 
This study was performed at a rural public elementary school in south central Ohio. The student population of the school is approximately 300 with $98 \%$ being Caucasian, $35 \%$ being economically disadvantaged, and $12 \%$ being diagnosed with a learning disability. The focal point of this study was a group of students in two fourth grade Language Arts and Social Studies classes. The school district in which the study took place divided their students into four sections. Each class was comprised of students heterogeneously selected by the school's principal before the school year started. Each section was a mix of students with a balance of academic abilities and behavior rankings based on the prior year's teacher rankings.

Significance of the Study

With so much time, energy, and money being used for technology in education it is important to try to get a handle on the value of technology in education. Finding students' perceptions about benefits and limitations will better help us understand effective ways to use technology in language arts and social studies classrooms in today's elementary schools. While student's perceptions are highly valued, the effect on academic gain is equally, if not ultimately, more important. The research that combines both student perception and academic gain at the elementary level is greatly lacking. Much of the research involving technology perception is often performed at the college level (Apperson, Laws, Scepansky, 2004; Frey \& Birnbaum, 2004; Kirwood \& Price, 2005; Gustafson, 2004). Much of the research at the primary levels have been conducted overseas such as (Shenton \& Pagett, 2007; Martin, 2007; Slay, Sieborger, HodgkinsonWilliams, 2008; Warwick \& Kershner, 2008; Wall, Higgins, Smith, 2005) or in Canada (Starkman, 2006). Furthermore the research that focuses on academic gain has been 
sponsored by technology companies such as the Apple Laptop study, and those studies conducted by Knowlton (2007) the CEO of SMART technologies. Therefore there is a need to study both student perceptions and academic gain through non-biased means. By examining the perceived benefits of IWBs, better lessons and teaching techniques can be developed, building on those perceived benefits. On the other hand, by taking into account the limitations of IWBs, lessons and teaching techniques can be developed that steer away from pitfalls. Also by tracking academic gain, insights into effective teaching practices can be created. So in turn, studying student's perceptions with academic gain, should lead to the creating of best practices concerning the IWB. Hoopingarner (2009) stated the best practices of using technology should include technology to increase input, give more opportunities for practice, be interactive and tool for tasked based learning. Finally the motivation of students is a key component of any high-quality teacher. Therefore the ability of IWBs to motivate and engage students should be considered. Proponents of educational technology have made numerous claims as to the advantages of technology. While critics are quick to downplay any positive benefit by pointing to the costs and limitations of the technologies, finding students' perceptions is of the utmost importance, whereas the students are the ones consuming the educational technologies.

Based on the principles of moving from a teacher centered classroom to a student centered classroom, the students should have ownership and a voice into the direction of the educational technologies. While measuring academic gain will help give a truer picture of how teachers can and should be implementing activities based on the IWB. 


\section{Methods of Procedure}

Research questions:

1. What are the perceived benefits and limitations of an IWB compared to traditional teaching techniques in a fourth grade language arts and social studies class?

2. In what ways can the use of IWBs be improved in a fourth grade language arts and social studies class?

3. What were the effects of using IWB on student achievement in a fourth grade Language Arts classroom?

This is both a quantitative and a qualitative action research study. The qualitative data focuses on student perceptions of an IWB. The quantitative data was based on academic gain by tracking four weekly language arts short cycled assessment scores. The qualitative data was collected through interviews and student journals. While analyzing the qualitative data I looked for themes of benefits, limitations, and areas of improvements of the IWB. The quantitative data was comprised of four weekly language arts short cycled assessment scores. Each class was compared to a baseline. The baseline was determined by the previous grading period average. These assessment scores of both classes were compared based to the class that was taught with the use of IWB and the class that was taught with out the use of IWB. The comparison was done over a four week period. As an action research this study was conducted in a fourth grade classroom.

My sample consisted of two four grade language arts and social studies classes. Class A had 16 students, and class B had18 students. I collected both quantitative and qualitative data from each of the 34 students. This study lasted for four weeks using a 
within subject design with a counterbalancing of order. The following pattern was established:

Class A: 2 weeks IWB, 2 weeks no IWB

Class B: 2 weeks no IWB, 2 weeks IWB

The classes met each day for 2 hours and 15 minutes which was an established pattern form the start of the school year. Each class received the same content and assessment. The only variable was the use of the IWB. The uses of the IWB during this study were to show PowerPoint presentations, display visuals, note taking, completing worksheets, and playing interactive games. For the class which was not using the IWB I used an overhead projector with transparencies, displayed pictures, wrote notes and completed worksheets on a dry-erase board, and played similar games. These were my traditional teaching methods which have been positively evaluated by my school's administration in the past.

The research focus was on the students' perceptions of an IWB and its impact on student academic gain. During the four weeks of the study students recorded their experiences in regards to the use of the IWB in journals. Each journal entry included the date; any perceived benefits of the technology, any perceived limitations of the technology, and lastly any suggestion for improvements. At the conclusion of the study I interviewed each student again; the interview questions focused on perceived benefits of the technology, perceived limitations of the technology, and lastly suggestions for improvements.

For the quantitative data I used four weekly short cycled assessments. These assessments were the same textbook manufactured assessments that $I$ had use during the 
entire school year. Each Friday the students were given an assessment over the content covered during that week.

In analyzing the qualitative data, I coded the students' journals and interview responses. During coding I discovered common topics about the perceived benefits of the technology, perceived limitations of the technology, and suggestions for improvements. For the quantitative data each assessment was scored based on a one hundred point scale. The assessments of both classes were then compared to a baseline. The baseline was determined from the previous grading period's class averages. 


\section{Chapter 2}

\section{Plenary Literature Review}

\section{Technology and Learning Theories}

Educational technology has ramifications in the three major learning theories.

The learning theories are the Behavioral Psychology Theory, the Cognitive Theory, and the Constructivist Theory. Each learning theory has unique aspects that are apparent in technology.

Technology acting as a stimulus or as a reinforcement can clearly be found.

Games of drill and practice operate under the behavioral theory which was made know by Ivan Pavlov. Cues are often embedded in games that positively reinforce desired outcomes. Marzano (2009) found achievement gains by using IWB as a "reinforcer" moving correct answers to specific locations, or by signaling correct responses with virtual applause. One way teachers can create games is with the use of non-linear PowerPoints. Non-linear PowerPoint presentations operate under a Behavioral Theory as well. A non-liner PowerPoint is not sequential; the presentation has the ability to skip from one slide to another without going through the standard slide progression of slide 1 , slide 2, slide 3, ect. Sadler (2002). The nonlinear PowerPoint provides the user with reinforcements when the student selects either a correct or incorrect answer. Interactive programs deploy the uses of stimulus and response to move the user through the presentation at an individualized order and pace. When using a non-liner PowerPoint a student response to a stimulus, which in turn moves the presentation to the next slide. However the next slide to appear is based on which stimulus the user interacted with on the previous slide. 
Cognitive Theory pertains to educational technologies and specifically pertains to IWBs. Alessi \& Trollip (1991), make note that information is required to be received with ease. The position of the information affects our attention to the information and our perception of the information, and differences and changes attract and maintain our attention. These aspects undoubtedly relate to IWBs. Also noted are the many references to active learning and motivation as being a major component of educational technologies and IWBs. The IWB's large size and ability to incorporate both sound and color lends the IWB to fall under the Cognitive theory umbrella because Cognitive theories place emphasis on both auditory and visual components for processing information.

Finally the use of certain educational technologies that accentuate the actions of the learner rather then the procedures of the teacher falls under the Constructivist Theory. The Constructivist theory states that learning is an active process which knowledge and meaning are constructed based upon current and past experiences (tip.psychology.org 2010). Educational Technologies such as WebQuest and other discovery learning techniques place their focus on the learner. Additional Constructivist aspects of educational technologies are found in the prominences of cooperative and collaborative learning.

Regarding educational theory, the IWB is often employed to integrate one or more of these classic learning theories simultaneously. The ability to integrate multiple learning theories is a major strength of the IWB. The adaptability and multiple use functions of the IWB help to create the integration of these classic learning theories. 


\section{Summary of Relevant Literature}

Honey, McMillan, and Carrigg (1999) are critical of early technology research conducted in the 1970's and 1980's claiming that research only focused on whether technology improved student learning, but did not factor in any other aspects such as the practices of the teacher, student experiences, or content. This separation of technology led them to what others have found. Technology by itself does not imply learning (Driscoll, 2002; Furr, Ragsdal, \& Horton, 2005). Teacher practices are a significant part of studies on teaching and technology. Most often researchers have called for change in teaching styles and techniques when using technology. Dwyer, Ringstaff, and Sandholtz, (1991) maintain educators' beliefs about schooling must adapt in a technology rich classroom. There must be a change in teaching from traditional lecture, recitation and seatwork to a more open, individualized, cooperative, project-based system. Handal \& Herrington (2004) echo the same message of changing the role of the teacher and learner. McNabb \& Hassel (2000) also call for a shift from teacher-centered to learner-centered practices. Dede (1997) sees two categories and makes the distinction between training and educating. His studies found that technology best works when training such skills as basic math, or anytime there are a limited number of correct answers. However education according to Dede (1997) has multiple correct answers, so technology should not be used to replace human relationships. Similarly in creative disciplines, such as creative writing, we need human relationships.

Most researchers Kennewell \& Beauchamp (2007); Apple lap top (2009); Dede (1997) agree on the need for professional development to change the role of a teacher. If change is going to occur, professional development must be an imperative part of 
integrating technology. However, researchers differ on how professional development should be put into practice. Some state professional development is open and free, allowing teachers to discover, as the case with McNabb \& Hassel (2000), who found that teachers in their study had taught themselves how to use the Internet in the classroom. Glover and Miller (2007) state professional development must be institutional and cannot rely on teachers to show co-workers how to use new technologies. Others stated that professional development must focus on creating student-centered instructional practices instead of just computer skills (Harvey-Woodall 2009).

\section{Technology Implementation}

Implementing technology has many challenges. I have seen at my school veteran teachers are resistant to change their teacher created materials and resources over to a digital format. Additionally having access to fully functioning and up to date technology is a challenge. Lastly, in my school often the scope of learning with technology stops at basic keyboarding. To help make the implementation of technology a success, Knowlton (2007) suggests three key components to successful ICT implementation. First school districts must have a vision that goes beyond just learning about technology, but instead using technology to learn. Secondly, professional development of teachers must be ongoing. Finally, school districts must create environments that lead to the best experiences for students.

\section{Benefits of Educational technology}

Knowlton (2009) states the problems in modern schools are results of students being detached from the learning process and Knowlton maintains that technology can better engage students. A study conducted by Slay, Sieborger, and Hodkinson-Williams 
(2007), in which they used an IWB, found the motivation of being current and an increased interest level by students when technology was involved. Other studies such as the Apple lap top (2007) found students said that because of the use of technology, the students, were more interested in school. Along with an increased interest in school the Apple study found 54 percent said they were better able to understand their work. Apperson et al. (2006) commented that students also said material was more clearly presented, and easier to understand. Students often perceive the use of technology to be advantageous. Researchers such as Susskind (2008), Slay et al. (2007), and Apperson et al. (2006) have found that students believe that it is easier to take and understand notes from computer generated presentations and that they were more likely to remain focused on the content. Overall the students found that bringing multimedia content into lessons as an advantage to using technology.

Technology also provides curriculum opportunities that would otherwise be unavailable. Miners (2009) stated that using technology is not about the technology but about the life skills the technology builds in students. Opportunities in advanced subject matters or rare subjects such as foreign language can be made more readily available due to technology. Additionally technology could substitute the use of extensive laboratories that may be too expensive for schools (Dede 1983).

Additional benefits to using technology and IWBs is the ability to create Internet based activities. Internet-based activities help teachers meet an assortment of needs by allowing for lessons to be tailored to individual needs (McNabb \& Hassel 2000). Another advantage pointed out by Lee (2002), regarding social studies is that the internet has given access to primary source documents, which Lee claims creates a more learner- 
centered lesson, and in turn gives the student a more personal understanding of history. Similar benefits have been found for literacy. McNabb \& Hassel (2000) found positive results occurred when teachers used Internet- based learning activities for literacy. These positives included the fact that students claim reading was more enjoyable. Reading fluency increased as did critical reading skills. Lastly, students had an improved understanding of materials. Leu (2002) points to the Internet and ICT as changing the nature of literacy and literacy learning.

Adaptability is yet another advantage of technology. Kennewell and Beauchamp (2007) studied how ICT was being used and noted that technology, when compared to traditional media such as textbooks, is much more adaptable, and has fewer limitations.

Handal \& Herrington (2004) studied technology's effect on field independence (FI) learners. Their findings suggest that technology-rich learning environments provide an environment where FI learners have more opportunities to succeed. Technology-rich environments benefited dependent learners as well.

\section{Limitations and Barriers of Educational Technology}

Technology has many educational benefits, but there are also limitations and barriers that come with educational technology. Yanik \& Porter (2008) interviewed teachers about using technology. They have found two major hurdles for teachers using technology in the classroom, teachers stated being unfamiliar with programs and a lack of experience with knowing how to use technology. Slay et al. (2007) comments that students stated a teacher's lack of ICT skills as the biggest disadvantage. Others like Reedy (2008) stated that the programs themselves place barriers on education. Reedy 
noted that PowerPoint slides potentially discouraged students to think because they.only focused on what was contained within the slide.

Time is another issue that must be considered. Teachers often feel they do not have the time to find valuable technical resources Den Beste (2003). Hick et al. (2004) found that teachers stated that by using the Internet, there were too many sites and teachers were not able to find appropriate information. Teachers also point out when resources are found (Lue, 2002) students just surf, not taking time to read, but only wanting to see what is next. Time issues exist when dealing with teacher-made presentations. Teacher-made presentations like those made with PowerPoint can take hours to construct (Teach-nology.com, 2007). A study conducted by Hicks, Doolittle, \& Lee (2004) found that teachers do not use primary sources in social studies classes, because the teachers feel they have a lack of time to search.

Additionally, a lack of training, including both technical trouble shooting and using technology as an effective teaching tool, is also a limitation. Dede (1997) points out that teaching by telling and learning by listening makes a computer a "fire hose", spraying out information. He adds that classrooms are already drowning in data. Bradshaw (2002) calls this informational overload "navigational disorientation". Users become overwhelmed with the amiount of information.

The high cost of maintaining, upgrading and operating technology is difficult. Other institutions use technology to make improvements, such as lowering costs to operate, or to improve outputs. However, schools do not. Technology only raises the costs to educate (Dede 1997). Costs occur with buying new software, hardware, and maintaining and updating existing technologies. High cost is also a factor in availability 
of technology. In 2001, according to the National Center for Educational Statistics, the student to computer ratio was 5.4 to 1

Others have concerns about health and safety regarding the use of technology. Dede (1983) cautions human interaction and interpersonal skills may be underdeveloped by spending so much time with machines instead of people. School districts often use blocking software to prohibit and restrict sites that are deemed inappropriate. However these blocking software are certainty not 100 percent effective. The blocking software also limits the use of some sites that are appropriate. Yet another threat is viruses, or hackers that try to reach computers over the Internet. A Firewall is required to screen out hackers, viruses, and worms that try to harm computers (Microsoft.com, 2009). Miller, Thompson, \& Franz (2009) list three major threats to the health and safety of students while working online. First Cyber bullying, a study by Ybarra \& Mitchell (2007) found that almost 35 percent of students between ages 10 and 15 had been harassed while on the Internet as cited in (Miller, et al. 2009) Secondly online predators pose an obvious threat. Thirdly marketing and advertising is a threat that is easily overlooked. To combat these safety concerns (Miller, et al. 2009) calls for a current Acceptable use policy that needs to be proactive when dealing with cyber issues.

Lastly the use of copyrighted materials is a problem. Copyrighted materials are easily transmitted via the Internet and used in classrooms and as part of distance learning. The use of copyrighted material has become such a problem that the Teach Act Guidelines had to be created (Simpson, 2005). 


\section{Types of Information and Communications Technology}

One of the most widely used ICT in schools would be multimedia presentations. These presentations are created with software, mostly PowerPoint. Often used in conjunction with multimedia presentation created by PowerPoint are IWBs. Branzburg (2006) describes the whiteboard as a live computer desktop, which when touched, can do all functions of a desktop such as open files, and can draw geometric shapes as well as underline. Then the screen can be saved along with any annotations to be shared or printed. The use of digital video is another popular practice. These videos can be viewed either on a standard television or with an IWB. ICT has created a use for computer generated organizers. Inspiration is software that is used for visual mapping; outline and writing that incorporates digital pictures such as clip art to represent ideas. Inspiration can be used to create concept maps (Taylor \& Duran, 2006.)

Another application of PowerPoint lines with its non-linear capabilities. During presentations PowerPoint moves in a linear format, which coincides with the same format as a textbook. However with the use of action buttons, PowerPoint can be designed in a nonlinear format allowing for self guided quizzes. The teacher poses questions with multiple answers. The student selects an answer which contains an action button. An action button is what moves the PowerPoint user from one slide to the next. Depending on the answer selected, the student will be moved to a new slide. If the answer is correct, the next question may come up, or there is a slide indicating a correct response. If the student gives an incorrect answer, the student is redirected to a slide containing correct information needed to appropriately answer the question. By locating action buttons with certain texts, the teacher can guide the users to correct answers, while pointing out the 
pitfalls that led the students to incorrect answers. Additionally PowerPoint can be used with traditional worksheets. By scanning the worksheet into a digital file, the worksheet can be used in conjunction with all the advantages of PowerPoint. Voice can be encoded into the new file; action buttons can be placed to guide the learner.

Virtual field trips are a computer based simulation of an actual field trip (Clark, Hosticka, Schriver, \& Bedell 2002). These field trips allow students to experience places otherwise too far or too expensive for travel. With many school districts cutting or limiting field trips, virtual field trips become a viable option. In addition virtual field trips save travel time. IWB's work well with virtual field trips because the IWB allow for the entire class to view the content without leaving their seats. In my own experience students have enjoyed virtual field trips but not as much as actual field trips.

WebQuests and Internet workshops allow students to use an Internet connected computer to search and find information. These activities are usually teacher designed. The teacher finds an appropriate web site and bookmarks the web site. Then the teacher designs activities so students can gather information. The students then choose information to gather. This choosing gives the students autonomy over which information is to be gathered and brought back to the group. The information is then shared with other students. (Leu 2002).

\section{Student perceptions of technology}

Generally students have a positive attitude of teaching with the use of technology. Yanik and Porter (2008) found that most students positively viewed the use of a computer for instruction. Apperson et al. (2006) found that students viewed the professor more favorably when technology was used and students claimed the material was more clearly 
presented than when technology was not used. Included in Apperson, students claimed to have had an overall better experience. Susskind (2008) found what others found Frey, \& Brinbaum, (2002), Kask (2000), Szabo, \& Hastings, (2000) that computer presentations had strong positive influence on students' attitudes and self-efficiency.

\section{Interactive whiteboard}

Currently there are 5 major companies that manufacture IWBs. The largest by units sold is Smart followed by, Promethean, Einstruction, Numonics, and E-Beam (Rey 2009). The current cost of IWBs ranges from $\$ 1500$ to around $\$ 16,000$ according to an article published in T+D in 2008. IWB's current use in American classrooms is 1 in 5 Curwood (2009). IWBs have generally been welcomed by teachers (Levy 2002). IWBs offer teachers a wide range of benefits. IWBs can write, erase and execute mouse functions with one's finger tips. Also IWBs can be used to digitally write over web sites, write on videos, and then capture your work, and finally save Starkman (2006). Additional positive implications deal with note and note taking. Branzburg (2006) pointed out that students can participate in the presentations instead of only copying from the board when notes are printed out. Reardon (2002) pointed out that notes can be saved and stored for students who were absent. Apperson, J. M., Laws, E. L., \& Scepanky, J.A. (2004) found students to be more actively involved in learning than solely focusing on copying information directly from slides.

IWBs give greater opportunities when accessing web content and streaming videos. Paoletti (2004) the teachers can stop at opportune moments and highlight, or annotate sections by text or other graphics that can be saved for later use. 
Clearly the visual components of IWBs have great value to educators. IWBs allow teachers to choose the size and color of font. IWBs also allow teachers to bring computer graphics to lessons. Many researchers point to the visual aspects of IWBs as being a benefit. Slay et al. (2007) noted that the biggest advantage of an IWB is the size of the screen. Edwards, Hartnell and Martin (2002) also noted visual projection of an image on an IWB was better-quality then projecting it using an overhead transparency. A study by Pratt \& Davison (2003) mentioned the visual aspect of an IWB as being its greatest advantage followed by the kinesthetic aspect. Branzburg (2006) mentions how IWBs can impact special needs' students pointing to features such as large font, color of font, and clearness in which text is written compared to when written by hand. Branzburg (2006) also noted that the touch capabilities would benefit kinesthetic learners.

Furthermore IWBs cultivates a kinesthetic aspect because the user either teacher or student can manipulate objects such as text, or other graphics on the screen Pratt and Davison (2005). The functions of the IWB incorporate features of all four modalities, visual, auditory, kinesthetic and tactile. The IWB has the ability to integrate multiple modalities into a lesson.

\section{Specific uses of Interactive Whiteboards}

Researchers have noted the uses of IWBs in multiple subject areas. However specific to Language Arts would be story starters. A story starter is a prompt to start students in a writing activity. The large display allows for students to quickly glance back at the story starter to insure the student is writing on the correct topic. Daily test questions like those found on the Ohio Achievement Assessment (OAA) are clearly displayed large enough for all students to view. The test selections are also able to be viewed allowing 
the teacher to model how and where to find the answer in the selection. Worksheets and practice book pages can be displayed and annotated through use of an IWB. Finally, the IWB gives the ability for the teacher to display the students reading textbook. Often textbook companies such as the one used in this study Macmillan/McGraw-Hill have interactive programs that are built especially for the language arts skills of the lesson being studied. The interactive lessons work to build background knowledge, vocabulary, spelling and grammar. These lessons can be done either by an individual, or with the IWB, can be completed with a group of students. As mentioned before, PowerPoint presentation, both linear and non-linear can be exhibited to individuals or to the entire class. Another use of an IWB in a language arts classroom is noted by Dye (2003) in which Dye noted the use of word finds. The interactive capabilities of an IWB permit students to highlight words in a word find that is presented for the entire class to view. Additionally, correcting grammar such as punctuation and capitalization can be done by students with an IWB (Paoletti 2004). Lastly, teachers are able to create graphic organizers with the use of an IWB. The IWB allows teachers to create a variety of different types of graphic organizers to meet the needs of a particular lesson. Additionally the IWB can be employed to fill in the information onto the graphic organizer.

In the area of social studies IWBs have many uses. WebQuests in which students interact with primary sources, become a true possibility with an IWB. Virtual field trips allow students to view and experience parts of the world that before would have been impractical. Branzburg (2006) suggests having students create and display presentations. These presentations can be done as an alternative learning assessment. The generating of 
graphic organizers is yet another aspect that IWB can improve. (Boon, Burke, Fore, \& Hagan-Burke 2006) studied computer generated organizers as compared to traditional textbook instruction in a Social Studies class and found that computer created organizers increased content learning. Additionally the IWB allows the ability to display charts and graphs which the teacher can highlight and annotate. Mounce (2008) points out how IWB could be used along with free graphing software from the National Center for Education Statistics, which enabled students to create multiple types of graphs such as pie, bar, and line graphs. IWBs also make viewing large scale maps that are not common place in classrooms, possible. Viewing historical maps and other maps which are not frequently found in standard classrooms, such as elevation based and population based maps, becomes possible. Google Earth can show students places that otherwise would have been hidden from them. Lastly, as previously illustrated, IWBs have great advantages in note taking which applies in a social studies classroom.

Drawbacks to IWBs result almost certainly because of a lack of training. Reedy (2008) found teachers felt lack of training caused them to use IWBs in a less sophisticated way. Teachers were not doing anything they could not have done with a traditional whiteboard and an overhead projector. Another negative associated with technology as a teaching tool seems to result when teachers fail to appropriately adjust their teaching methods to take advantage of the technology. Apperson et al. (2008) found that students disliked PowerPoint when teachers read slides word for word without elaborating or discussing the slides any further. Other negatives include in some cases sunlight, made the viewing difficult Hall, \& Higgins (2005). 
Educational technologies incorporated into schools seem to have three major themes. First, educational technologies are becoming more and more prevalent and are going to be a major factor in the future of education. Secondly, research suggests that in order to use educational technologies effectively, a shift in teaching pedagogy must accompany the technologies. Teachers need to change from traditional methods to student-center methods (Dwyer, et al 1999; Handal \& Herrington, 2000; McNabb, Hassel 2000; Lee 2002). Then too in order to use technology effectively teachers must enhance their professional development in the use of technological tools. Lastly, technology is a useful tool, but it is not the end all, be all. Technology can not substitute well-polished teaching (teach-nology.com, 2007) and should be used to improve the art of teaching (Kent 2006). Kirkwood \& Price (2005) would add that the educational medium should not take precedent over the education itself. 


\section{Chapter 3}

\section{Methodology}

This is a quasi-experimental action research study based on a mixed procedure approach. Mixed research involves the mixing of quantitative and qualitative research Johnson \& Christensen (2004). The objective of this study was to discover students' perceptions on an Interactive Whiteboard (IWB) used in a classroom and to track academic gain. To be able to accomplish the first part of the objective, I taught two classes on a within subject design with counterbalancing of order. Throughout the first stage, A, I taught in my traditional teaching style. Throughout the second stage, B, I taught with the use of an IWB. Stage A was used as a baseline in order that the students could compare the IWB to traditional instruction. The Alternating design allowed for a comparison of students' impressions for a particular lesson both with and without the use of an IWB. The alternating counter balancing design permitted each class to serve as its own control. The entire study comprised of four weeks with each stage lasting for two weeks. I followed a pattern of:

Class A

Class B

\begin{tabular}{|l|c|c|}
\hline Week 1 & IWB & No IWB \\
\hline Week 2 & IWB & No IWB \\
\hline Week 3 & No IWB & IWB \\
\hline Week 4 & No IWB & IWB \\
\hline
\end{tabular}




\section{Dates of Stages}

January 25 - February $5 \quad 10$ school days

February 8 - February $19 \quad 9$ school days

In order to track academic gains, the classes' previous grading periods weekly language arts short cycled assessments were used to determine a baseline for academic gain. The lengths of the classes were 2 hours and 15 minutes, which met every typical school day. The content covered during the eight weeks was comprised from the Ohio fourth grade language arts and social studies standards. Each class received the same content and assessment. The weekly language arts test were the same MacMillan/McGraw-Hill textbook made test that had been used during the entire school year. The IWB was used to enhance visuals with the use of PowerPoint, graphics, and Internet sites. In class sessions without the IWB, I utilized an overhead projector, hand drawings on the dry-erase board, and a standard wall mounted 32 inch television. The use of an overhead projector, dry-erase board, and television are the traditional methods that I have used in my eight years of teaching. The traditional methods have been positively evaluated by my school's administration in the past.

During the study, on Mondays, both classes were introduced to the vocabulary words for the unit. The class with the IWB was shown the vocabulary words in context of the story by viewing the textbook on the IWB. During this time the vocabulary words were discussed by both the teacher and students. The IWB was then used to look up the definition of each vocabulary word that the students wrote down. After the introduction of vocabulary a reading skill was introduced. 
The reading skills covered in this study were, fact and opinion, techniques of persuasion, Author's purpose, sequencing, and summarizing. Once again the students viewed the textbook on the IWB and students read the story and identified the reading skill. As the students read, I used the highlighter on the IWB to highlight places in the story that contained the skill of that week. For the grammar lesson the IWB was used to show students a worksheet that introduced a grammar skill. The worksheet was completed by the whole group, with students being able to write the answers on the IWB. This allowed for everyone to see, hear, and write the correct answers. For spelling students were given a pretest and then used the Macmillan/McGraw-Hill's website, which contained interactive activities based on the week's spelling. Students interacted with the IWB by playing games that were derived from the spelling list.

In comparison, the class without the IWB, used the overhead with colored transparencies to introduce the vocabulary. With the transparencies, students read the vocabulary words in context of the story. Next the class discussed the vocabulary words and finally students used the glossary of their textbooks to look up the definition of the vocabulary words and wrote down the definition. The introduction of the reading skills also utilized the colored transparencies. Students read the story from both textbook and overhead, and I used a marker to highlight places in the story that contained the reading skill. The grammar lesson was done whole group with the answers being written on the dry-erase board. For spelling, students were given a pretest, and then played a spelling game called "Sparkle," where each student takes a turn saying a letter of the spelling word until the word is spelled correctly. Then the student whose turn it is after the last correct letter is given says, "Sparkle," which eliminates the previous person and the game 
moves to the next student and word. This continues until there is only one student remaining.

Tuesdays' lessons consisted of reading the main story selection and completing a graphic organizer, which demonstrated that week's reading skill. The class with the IWB used the IWB as well as textbooks to view and read the reading selection. The graphic organizer was also shown on the IWB. As the class read the story, I modeled filling out the graphic organizer. The information to complete the graphic organizer was identified by the students then highlighted in the story by the teacher the information was then discussed by the class. Finally the information was typed onto the graphic organizer by the teacher and then recorded by students onto their own graphic organizer. Tuesday's spelling lesson revolved around a grouping or sorting of the weekly spelling words. The words were to be grouped by vowel patterns, endings, or some other defining characteristic. The IWB was used to show students the worksheet which showed the pattern to be used in the sorting or grouping of the spelling words. Also students were given word finds that contained the spelling words. After finding the words a copy of the word find was shown on the IWB and students highlighted the words with the marking pen.

For the class without the IWB, the students read the main story selection in the textbook. An overhead with a transparency of the graphic organizer was used. The students identified the information from the reading selection to be used in the graphic organizer and I wrote the information onto the graphic organizer on the transparency. The students discussed the information and then copied the information from the overhead. For the spelling lesson the dry-erase board was used to show the identifying 
pattern of the spelling words and how to sort them. The word finds were then shown on the overhead with a transparency and students highlight the words on the overhead.

Wednesday's lessons consisted mainly of reinforcing the reading skill by completing practice worksheets. The class with the IWB could view the worksheet on the IWB and then complete the worksheet. Next the IWB was used to show the correct answers which allowed each student to monitor their own progress. Additionally as the practice papers were being checked, I pointed out where the answers were found by highlighting places on the worksheet. Spelling lessons for Wednesdays involved the students writing their spelling words in a sentence. The list of words was shown on the IWB.

The class without the IWB completed the same practice pages and answers were then checked by the teacher writing the answers on the dry-erase board. I also told the students where the answers were found. For the spelling, a copy of the spelling words was written on the dry-erase board.

Thursday's lessons were comprised of the weekly reading skill being used in old Ohio Achievement Assessments. Students were given reading selections from previous OAAs that contained questions that related to that week's reading skill. Students read the selection and answered the questions that went with that selection. The IWB was used to show the selections from the Ohio Department of Education's website. Students shared their answers and then shared where in the selection they found the answers. The students then highlighted where the answers were found. The class without the IWB used copies of the old OAAs on transparencies. For spelling, proofreading worksheets that contained misspelled words were viewed on the IWB. Students pointed out the 
spelling mistakes and marked them on the IWB, as well as on their own worksheets. For grammar, the same type of proofreading was done by reading a paragraph that contained grammar mistakes. Students used the IWB to highlight the errors and then fixed the mistakes on their own worksheets. For the class without the IWB, the overhead projector and dry-erase board was used.

Friday was test day. Each class with and without the IWB took the same pencil and paper test. The tests were created by the textbook manufacturer. The test contained a total of 14 questions. Two different types of questions appeared on the test; multiple choice and short answer. The test consisted of four vocabulary questions, four reading comprehension questions based on the weekly skill, three grammar questions, and three spelling questions. The assessments were paper pencil tests just like the ones given during the entire school year.

Throughout the four weeks of the study, students recorded in journals their class experiences with technology. At the end of the daily lesson, students were asked three questions about the use of technology. The first question was: if the IWB was used today and was it helpful to you? If the IWB was not used, were the other technologies (overhead projector, dry-erase board, or television) helpful to you? The second question with respect to technology was: what did you not like or what was not helpful about today's class? The third question was: in what way could technology have been better used for today's class? Students wrote their answers to these questions three days a week. The same three questions were asked each day. At the conclusion of the study I interviewed all students. I asked about their perceived benefits and limitations of the 
IWB. I additionally asked for suggestions of possible improvements in the use of the IWB.

Rationale for the Method

Action research is a common method used to research local specific problems (Johnson \& Christensen, 2004). However action research is a continuing process due to the fact that most problems are not fully resolved by a single study (Johnson \& Christensen, 2004). The educational concerns I centered around were the perceived value of an IWB in an elementary classroom and an IWB's effect on academic gain. The value was estimated by gaining insights into students' perceptions of IWB and in the academic gain. The results became stepping stones for elementary teachers' future applications and uses of IWBs.

\section{Population of the Study}

The Population of this study consisted of fourth grade language arts and social studies students. 34 fourth grade students participated in this study. The student population consisted of 17 females and 17 males. The results have the most degree of external validity for rural, public elementary school students. The findings of this study are most applicable to Caucasian students in the Midwest with average to below average socioeconomic levels because of the population of this study.

\section{Sample}

Sample criteria. The participants used in this study were the students assigned by the normal school district's procedure. I collected data on all students in my classes. Class A consisted of 16 students and Class B consisted of 18 students. Language Arts 
and Social Studies are required subjects as part of the school district's elementary curriculum.

Rationale for sample. I used my assigned language arts and social studies classes because that is the most practical population for this study. Achievement of random assignment of students is unrealistic because of the elementary school setting. I collected data on all of my students to attain a $n$ of 34 students. By combining the two classes, enough data was collected to grant saturation and provide for adequate external validity for the intended purpose of this study.

Methods of sampling. Sampling from the population took place through class assignment. Class assignment was conducted by the school's principal before the current school year began. Class assignments were based upon the previous year's teacher ratings. The school district's goal is to create a balance based on both achievement abilities and on behavior. No sampling took place in the data collection process because data was collected from all the students. My classes would represent a sample from rural, public, Midwest elementary school students.

\section{Procedure}

Instruments. The instruments used to collect the data on student perceptions in this study involved students' journals and interviews. Daily, students were given the same journal prompt and asked to write at least one sentence for each question in the prompt. The questions for the prompts were as follows:

\section{Benefits:}

1. If the IWB was used today, in what ways was it helpful to you? 
If the IWB was not used, in what ways were the other technologies (overhead, dry-erase board, television) helpful to you?

\section{Limitations:}

2. With respect to technology, what did you not like or what was not helpful about today's class?

\section{Improvements:}

3. In what ways could technology have been better used for today's class?

The interview questions were also based on the benefits, limitations, and improvements (Appendix A).

To track academic gain weekly short cycled assessments were used. I used the previous grading period language arts assessments scores to develop a baseline for each class. Then I compared the weekly assessment scores of which the IWB was used to those test scores without the use of the IWB. The weekly assessments were made by the textbook manufacturer Macmillan/McGraw-Hill and contained fourteen multiple choice and short answer questions.

Pilot study. The pilot study took place four weeks into the study. After the first $\mathrm{AB}$ cycle I performed semi-structured interviews with five students from each class to field test the interview questions. Those students were randomly selected by drawing names from a container. The information collected during the first round of interviews helped me revise the interview questions.

Data Collection methods. Two major types of data collection took place concerning students' perceptions: student journals and interviews from both classes. The students recorded their impressions in a journal three days a week. The journals were 
kept in the classroom and distributed at the end of class. Students dated the entries and responded to the three prompts each time they wrote in the journal. The second set of data came from the semi-structured interviews that I conducted with each student at the end of the eight weeks. I completed all of the interviews within one week of the end of the study. Each interview lasted 5-10 minutes. I recorded the students' responses to the questions. Academic gain was measured by weekly language short cycle assessments. The language arts assessments were given each Friday during the four week study. The previous grading period's assessments scores were used to determine a baseline for academic gain. The weekly assessments were generated by the Macmillan/McGraw-Hill textbook company. The assessments contained fourteen multiple choice and short answer questions. Each assessment consisted of a one page reading selection followed by four vocabulary questions, four reading comprehension questions, three grammar questions, and three spelling questions. The weekly assessments were the same assessments that had been used during the entire school year.

Relevant ethical considerations. This action research project created no harm to the students involved. I taught in a customary manner which had been positively evaluated by the school's administration. The only difference included adding an IWB as a treatment to measure students' perceptions of an IWB's benefits, limitations, and areas of possible improvements. Because participants were minors, I received permission to participate from the students' parents/guardians. Parents and students were informed that confidentiality would be kept throughout the study. During the write up names were given pseudonyms. Additionally participating in the study would have no effect, either 
positive or negative, on a student's grades. Students' perceptions, either favorable or non-favorable, would not affect their classroom grades.

Treatment variable. The treatment variable was the use of an IWB which was controlled within the two classes. The variables that were assessed were the student's perceived benefits, limitations, and area of possible improvements in the use of an IWB. Additionally I tracked academic gains. I controlled the variable by teaching with the IWB, and teaching the same lesson without the IWB. Also a baseline of grades without the use of the IWB was used from the pervious grading period.

Methods of data analysis. Students' journal entries were organized by date, which allowed for comparison of IWB use and traditional teaching. Each interview was transcribed and organized according to questions. Data analysis involved coding. The first round of coding happened by comparing predominate themes that showed up throughout the data. As I coded that data, I added codes that emerged and deleted codes that became infrequent. The process led to a master list of codes. The master list was then used to organize the data collected from this study. The master list of codes included, visual, audio, interactive, engagement, help learning by, limitations, distracting, and drawbacks these themes were then further broken down into subcategories. For example the visual theme was then broken down to the subcategories of websites, seeing answers, highlighting, seeing the textbook, more information, videos and PowerPoint. Test scores were tracked both during the use of an IWB and without an IWB those assessment scores were then compared using a t-test and an ANOVA.

Safeguards to internal and external validity. To help with issues of validity I underwent several strategies. Those strategies included the use of self-reflection, 
participant feedback, low-inference descriptors, and negative-case sampling. I did selfreflection throughout the study. As part of the results of this study, I noted how my background may have affected the research.

Another attempt to protect validity employed the use of participant feedback. I shared my preliminary conclusions with a focus group. This was done to ensure that my findings were on par with the students' views. Another way I tried to manage researcher bias was by negative-case sampling. I intentionally looked for cases in the data that disconfirmed my own expectations.

A final strategy to promote validity used was low-inference descriptors. I included many direct quotes, so to clearly express the perceptions of the students. To safeguard the academic gain measurement, the same textbook generated assessments were used both to determine an academic baseline and as part of the study.

The within subject design with counterbalancing order of the study allowed for each class to be its own control. That helped maintain validity since students had wide ranges of abilities and attitudes toward school. Students' abilities and attitudes could pose a threat to affect their perceptions of the IWB.

As for the data collection of students' perceptions I employed the strategies of both method and data triangulation. The method of triangulation occurred through the use of both the journals interviews. The data triangulation occurred by using more than one data source as in the multiple interviews and two waves of interviews. The final precaution was that students checked the transcriptions of their interview to help insure the correctness of the data. Data collection of academic gain was determined by a weekly language arts assessment. 
The results of this study will not be able to be generalized to a large population since random sampling was not possible. The study having non-random sampling does negatively affect the external validity. However action research's goal is to deal with local issues. External validity becomes secondary to the greater purpose of finding perceptions of an IWB among my student population while at the same time tracking academic gain. These findings can be to some degree generalized to similar groups. 


\section{Chapter 4}

\section{Qualitative and Quantitative Analysis}

While analyzing the student's perceptions of the IWB in a language arts classroom compared to an overhead projector, several educational themes were noted. Additionally student achievement was tracked by weekly language arts assessments. The assessments covered the content that was delivered through instruction with the use of an IWB or an overhead. During the IWB phases I used an IWB and gave a set of notes to be taken by the students. An IWB was used to view the textbook, view internet sites and to display PowerPoint presentations, both teacher made and other presentations found on the internet. Additionally an IWB was used to display pictures that related to the language arts content. An IWB was also used to complete worksheets, and the worksheets were displayed on an IWB. Then either the teacher or students wrote with the pens to fill in the worksheets. Lastly, students interacted with an IWB by playing spelling games from the textbook manufacturer's website.

While using the overhead projector, the same note taking and other activities were employed. Notes and colored transparencies where displayed by the use of the overhead. Internet sites and PowerPoint presentations were displayed on a standard 32 inch television. Pictures were either drawn on a dry-ease board or shown as a hard copy and passed around the room. Similar spelling games were played with the entire class. Each class was taught as similarly as possible with the exception being the variety of technology being used.

Analyzing the students' perceptions of the IWB, compared with the overhead projector produced several important educational topics. The benefits that were noted 
included the increased interests in classroom content, as well as students perceiving learning more as a result of instruction with the use of an IWB. Students also noted a few drawback and limitations associated with the use of an IWB, which included mainly technical difficulties or user errors. Students' ideas for improvement mainly described maintaining current practices with an adjustment on frequency. Students' main suggestion was to simply use an IWB more. Interesting features of $I W B$

Increased interest. All students said that the use of an IWB made them more interested in class. However students gave a range of reasons as to why. Students mentioned the internet, games, videos, web quest, and interacting with the IWB as creating a higher interest level in classroom content and activates. Jeremy stated, "I'm more interested when we get to interact with the smart board." Additionally seven students noted that having more information and seeing the textbook on the IWB also led to a higher interest level. Nick said, "I like to see where the answers go. That helps me pay attention." The use of color was also a factor in the increased interest level. One student said, "I think it's cool because we do a lot more than with the overhead and its in color." The use of more pictures increased the interest level. Chance stated that, "the pictures help by making class more interesting." The students simply believed the IWB was more fun, which in turn added to an increased interest level. Lastly due to the size of the IWB not being as large as a traditional chalk board, students were required to sit closer together so that every student could view the IWB. The new seating arrangement gave the class more of a team feel. Brittany said, "I just like it. We all work together to get our work done. Before it was like we just sat there and did our own work but now we 
are closer so we help each other." Students also noted that the seat change made class more interesting.

Perceived learning more. Students perceived learning more as a result of instruction with the use of the IWB. Students felt they learned more with the IWB for a variety of reasons. First students believed that the IWB gave them more information, which in turn led to them learning more. Students claimed that PowerPoint presentations and websites gave them additional information. Jill remarked, "We do more with the internet. It has more information so we learn more." Secondly students noted the IWB made class move at a faster pace resulting in the students feeling they were learning more. The IWB was credited for making the pace of class faster because the IWB was easy to use. Lexi, said, "We can do more because the smart board helps us write and do our work faster." Additionally students also mentioned the work was made easier by the IWB, which also led to a faster class pace. The final reason students gave concerning the perception of learning more was the increased engagement in class driven by the multimedia aspects of the IWB. Buster claimed, "The games help me learn more."

Perceived benefits of the overhead included similar aspects as the IWB. Students describe being able to see the answers easily as the number one benefit to the overhead. Students also noted that the overhead was easier and faster-for the teacher to use. Students noted that there were fewer technical difficulties with the overhead. In general students felt the simplicity was one of the greatest strengths of the overhead. One student pointed out that they liked having only one page of information on the overhead at a time, while another student liked working as a whole class with the overhead. However when compared to an IWB the overhead had many more drawbacks. Interest and engagement 
were the main drawbacks. Students listed plain and boring as the primary drawback to the overhead. Sebastian asked, "Where is the inspiration? The overhead is just boring." One student mentioned not liking to move seats to see the overhead.

Components of the IWB. Students noted several aspects of the IWB that they felt benefited them educationally. Those features included the visual, interactive, and auditory components. The visual features of the IWB allow materials to be displayed in an easy to view manner. The interactive component allows the students to interact with the IWB by a touch of the screen either with a finger or pen. The auditory component is comprised of the sound either embedded in the PowerPoint presentations or by using the auto read feature. Students, or the teacher, highlight the text to be read and the text is read out loud. This can be used for a single word or an entire text.

Visual. The visual aspects of the IWB were viewed as a positive. Students mentioned visual twenty four times as how the IWB helped them learn. Students mentioned liking to be able to clearly view answers. Jill stated, "I like to see exactly what we are working on." Being able to see both textbook and worksheets on the IWB was mentioned frequently. Students also noted that seeing examples from the textbook helped them learn. Bryce pointed out, "I like it when the teacher highlights right where the answer is, that helps me." Seeing content in color also had a positive effect on how the students viewed the ways they were being educated. Students mentioned viewing websites and PowerPoint presentations led to both an increased interest and a perception of learning more. Nine students stated that they believed the IWB helped them learn because they saw more information from internet sites. Brittany said, "We can go to websites and find more. Being able to see websites really helps me learn more." 
PowerPoint helping students learn was listed by thirteen students. Additionally students believed the visual aspects helped to teach them faster. Pictures and videos from the internet were also stated by three students.

Interactive. Interactivity of games was mentioned fourteen times by students when asked what it was about the IWB that helped them learn. Interactive games was also the most frequently given answer on how the IWB made class more interesting. Eighteen students noted that by playing games, class became more interesting. Games were not mentioned during the class without the use of the IWB even though the class did play games during that time. Additionally playing more games was the number one comment on how to use the IWB better, and was followed by the suggestion of letting the students use the IWB more. "I like it when we get to write on the Smartboard." stated Josh.

Auditory. Two students stated that having the IWB read to them was a benefit to them learning. Additionally sound capability for PowerPoint and websites were noted as increasing interest in classroom content. However a few students did find the noises to be a distraction. Tony said, "Sometimes the noises are just silly and don't have anything to do with what we are working on."

Student use. All students claimed that the IWB was easy to use. Walker said, "You just go up and write. It's pretty easy." Most remarked that they enjoyed using the IWB. When asked how the IWB could be used better, eight students said more games, followed by a group that said let the students use the IWB more.

Teacher use. Most students had no comment on what made a teacher "good" with the IWB. However a few students suggested the teacher should know about websites and 
the teacher should have good computer skills. Students also thought the teacher should use the IWB everyday.

General impressions. Students were asked to give a final statement about the IWB. All of the students' comments were positive. Brittany said, "It is fun and better to learn in color and pictures." While Bryce said, "It is awesome because you can type or write on it." Nick remarked, "It's pretty neat because it has all of our worksheets on it and that helps me."

\section{Limitations}

Students noted limitations with the IWB. The main area of limitations resulted from technical errors. Students mentioned slow loading time, or the computer "freezing up". Other technical quirks included the screen saver coming on after a few moments of inactivity. Other limitations included difficulties in writing while using the IWB. Fuzzy or out of place writing occurred if the IWB was not calibrated with the projector. Also students noted the crispness of the writing when using the pens. Similar problems occurred when trying to erase writing. Often the precision of the eraser would not allow for parts of words to be erased so students had to erase the entire words. Students pointed out that some difficulties occurred when trying to erase due to the fact that the students were still holding the pen. In order to operate the IWB only one pen or eraser can be taken out of the tray. So to erase the pen must first be placed back in the tray and then the eraser can be picked up and used. Students also noted an issue of a shadow of the person using the IWB. The projector caused the user to have to stand to one side or the other so that the user's shadow did not block out the IWB. The user needed to stand to the side of the IWB that also led to some writing difficulties. The IWB is not without its 
drawbacks. Others mentioned the screen needed to be tilted so that that the projector and IWB lined up. Other drawbacks included the fact of the educational games being childish, and the fact that some students felt the games were not challenging enough. During the onset of the study, a few students mentioned problems with dragging the words across the screen and the controlling of where the words were to be dragged. That problem became less frequent as the study progressed. Another drawback noted by students was, that they had to wait their turns in order to use the IWB. Lastly one student noted the class being taught in a whole group manner was a negative. Ninety Five percent of students said that there was nothing distracting about the IWB. A few students pointed out that sounds and the teacher's shadow were distracting. One student mentioned that some students got distracted by the sounds and animations during the games and lost focus on what they were trying to learn and only focused on making the sound or animation occur. Another student mentioned the tool bar and the extra ink copies that pop up when scrolling down as a distraction. In order to scroll down when overwriting, the previous answers needed to be erased, or the answers from the top of the page would move down as the page was moved. Again that occurred primarily at the onset of the study. Nearly half of the students stated that there were no problems with the IWB.

\section{Improvements}

The students also had areas for improvement on the use of the IWB. Most of the improvements centered on the idea of the students getting to interact with the IWB more. Students mentioned they wanted to play more games, watch more videos, and see more 
visuals. In general the students just wanted to use the IWB in the same manner as the class had been using it. The students just wanted to use the IWB more often.

\section{Quantitative Analysis}

The quantitative results came from weekly language arts assessment scores. The assessment scores were based on a 100 point scale as were the grading period average. The classes' previous grading period average was used to determine a baseline to compare the assessment scores with the use of an IWB and with out the use of an IWB. Comparisons were made based on whole class and across gender differences. The counterbalancing design enabled analysis to compare the effect of the use of an IWB on both groups. The quantitative portion of this study focused on student achievement through academic gain as a result of instruction with the use of an IWB. To measure academic gain weekly assessment scores from the two classes were compared. Each class was also divided in to subsections based on gender. Class A was taught for two weeks with the use of an IWB, while class B was taught the same material without the use of an IWB. After the two week period Class B was taught with the use of an IWB while class A did not use the IWB. The statistical analysis based on a $t$-test failed to show any statistically significant data at the alpha .05 standard. Additional statistical procedures were to compare the gender sub sets of the classes; however the ANOVA test again failed to show any statistically significant data at the alpha .05 standard. Although there were no findings that met the definition of being statistically significant, as a result of this study two important trends were discovered. The first trend that the statistical analysis revealed was that the largest gain in test scores occurred during test one. Class A the class with the use of an IWB had a mean gain of 8.56. The second perceptible 
trend occurred again with class A between test 2 and test 3 . Class A showed a drop of 6.38 between the two tests. As shown in Table 1. This drop corresponds with exchange of the use of an IWB back to a class without the use of an IWB.

Table 1

Mean gain scores of class A and Class B

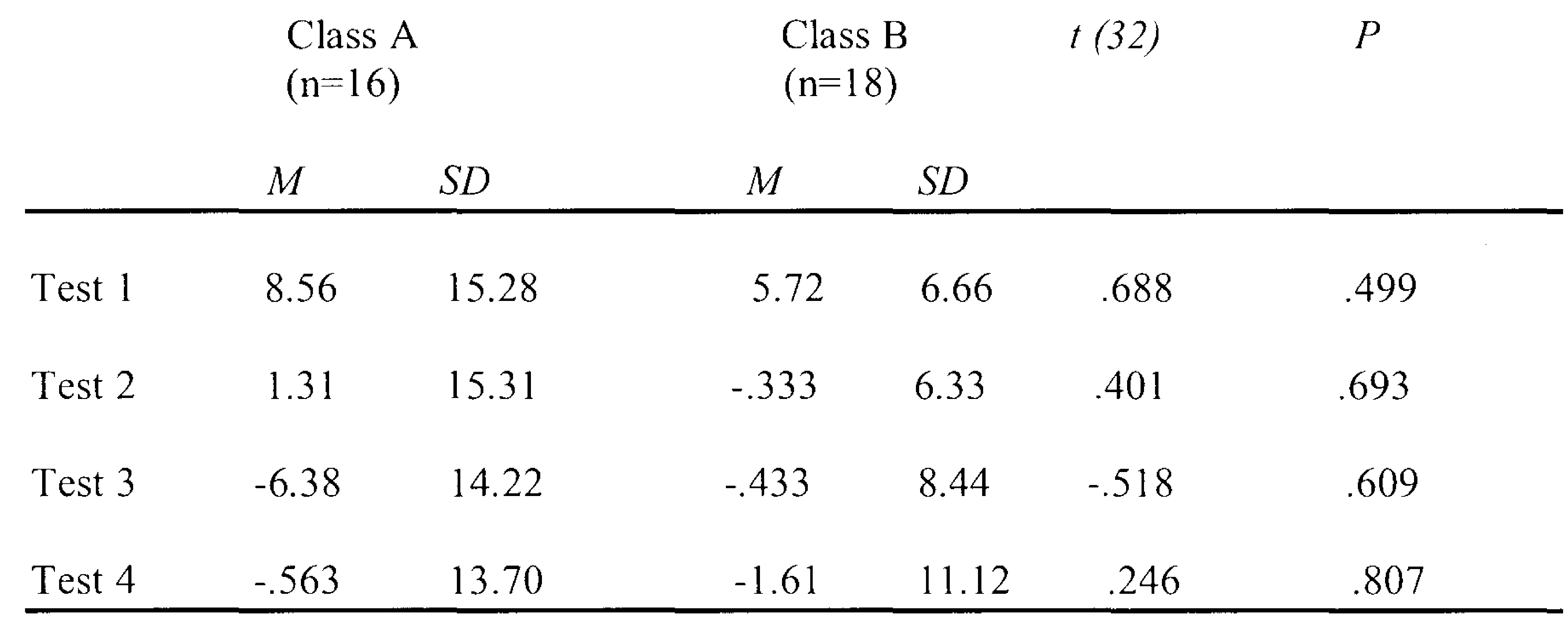

Note: Baseline used was determined by previous grading period averages.

Test 1 weekly language arts assessment class A taught with IWB, class B no IWB

Test 2 weekly language arts assessment class A taught with IWB, class B no IWB

Test 3 weekly language arts assessment class A taught no IWB, class B with IWB

Test 4 weekly language arts assessment class A taught no IWB, class B with IWB

\section{Summary}

This study clearly found the use of an IWB to be an effective educational tool that brought both enjoyment and a perception of learning into the classroom. The quantitative component of this study additionally supported the idea that the use of an IWB is an effective educational tool. The quantitative results showed an overall gain in student achievement through higher assessment scores when the IWB was employed; however, this gain was not at the .05 level needed to be statistically significant. The lack 
of statistically significant data was a result of the low sample size of this action research. The statistical trends that occurred should be noted. Students also noted limitations of the IWB and gave suggestions in which the IWB could be used more effectively in the classroom. 


\section{Chapter 5}

\section{Discussion and Implications}

The results of both quantitative and qualitative portions of this action research clearly show that an IWB can be used as an effective teaching instrument in a language arts classroom setting. Both components support the claim that the IWB is a useful educational tool that adds to the educational environment in a language arts classroom. The IWB is a valuable teaching tool, and the IWB's many educational benefits include engaging students with an increased interest level, improving visual aides, and creating a faster classroom pace. The limitations associated with the IWB are few and easily can be overcome with training. The most predominate benefits come from the positive beliefs about the IWB that the students hold. All students in this study made the comment that they viewed the IWB in a positive manner. Thirty-four of thirty-four students said they

preferred the IWB. Students' positive perception of the IWB was a result of the belief in one or more of the following: the IWB could teach the students more, the IWB made class more interesting, and students believed the IWB could teach them faster. The earlier stated perceptions about the IWB were shared by all students. However the students gave different reasons as to why they held the perception that they did. The reasons however were interchangeable.

\section{Potential Findings}

Likes. When asked what they "liked" about the IWB, students had a variety of answers that centered on the interactive games, visual aspects and the ease of operation of the IWB. However those factors were similar to the reasons of how the IWB helps students learn. When asked how the IWB helps students learn visual aspects, either PowerPoint, 
seeing examples from the book, or pictures were the most frequent answers. Interactive of games and students using the IWB was the second reason for how the IWB helped students acquire knowledge. Similarly the increased engagement and interest had many of the same factors. Students mentioned interactive games and websites as to why or how the IWB made class more interesting. Additionally the students noted the visual aspects of color, pictures, videos, and being able to see worksheets and textbooks increased their interest. Additionally the quantitative components of this study support the proposal that the IWB is a useful educational tool with the evidence that the IWB supported an academic gain.

Dislikes. Several common themes about the dislikes or drawbacks of IWB surfaced as a result of this study. The majority involved technical error or teacher error. "Slow" or "messes up" were the two most frequent comments. Teacher error led to other dislikes of the IWB. These limitations could be overcome with training and other technical education.

Technology. The IWB makes school more like life outside of school for students. Today's students interact with technology outside of the classroom on a regular basis. Students play video games; interact with computers and other technologies like television daily. The IWB allows students to be more active than the traditional discussion and simple paper and pencil worksheet work that is used in the majority of classrooms. The use of the IWB makes school more interesting and more enjoyable for students. Students also perceived learning more because of the IWB and the weekly assessment scores seemed to support the fact that students were learning more. 
As with any tool training is required. The teacher involved in this study has some technology training. Technology classes were both a part of his graduate and undergraduate programs. The teacher used a computer on a daily basis. The main training that occurred with the IWB was done by the teacher "playing around" with the IWB. Additionally teachers collaborated with each other as they discovered new features or new applications about the IWB. Formal training for staff occurred after five months of the installation of the IWB. That allowed teachers to become familiar with IWB and its uses at a basic level. Then the training could expand on the teachers' prior knowledge of the IWB and demonstrate other more advanced ways to using the IWB. Additionally the training sessions were used as trouble shooting sessions where teachers could get answers and training to specific problems. As noted, often technology training is not as effective as it could be because the training is viewed as too broad.

Consider space. The classroom in which this study occurred had been built before the installation of the IWB. So the classroom had to be adjusted to accommodate the new technology. Most often the blackboards or chalkboards are at the front and center of the classroom with the teacher standing next to the board teaching. This was the case with this classroom. The dilemma of where to place the IWB was quickly solved by simply placing the IWB in the back of the classroom. Now the front of the classroom became the back of the room and students simply just turned their desk in the opposite direction. The IWB was permanently fastened to the back wall of the classroom. This became ideal because it was out of the way of students bumping into the IWB as they lined up or changed classes. Additionally the projector was mounted from the ceiling. The mounting on the ceiling also allowed the project to be out of the way of students. 
Lastly, due to the size of the IWB not being as large as a traditional chalk board, students were required to sit in closer proximity to each other. However this new seating arrangement gave the class more of a team feel.

Increased pace and organization. The IWB made class move at a faster pace. This was mainly due to the fact that students could view exactly what we were working on. Telling students where things are located is not as conducive to learning as showing them exactly where to locate them. However, showing students usually meant the teacher had to walk around and show each student individually which takes more time. With the IWB, the teacher can show the entire class at one time. Also because the IWB is used in conjunction with a computer, the computer contains files and documents that can quickly be viewed. This shortens the set up time and transition time, which in turn leads to a faster class pace. With the use of the IWB, class also became more organized. Having a more organized class also increased class pace. The IWB allowed the teacher to set up class by simply opening files or documents or other applications to be used during class, then simply minimizing them to the bottom of the screen until they were needed. Having all classroom materials and documents at the bottom of the screen available with a touch of the screen or touch of the mouse was a great organizational tool. Increased variety and involvement. The IWB' gave a lot more variety to the activities in which the class was able to participate. The IWB allowed for interactive games, websites, videos and power point presentations that before were only able to be used on a limited basis. Those new applications gave much more variety over traditional worksheet, and lecture style teaching. However the IWB still allows for traditional teaching styles to occur. With the increased variety of classroom activities came an 
increase in the involvement of the students. Increased involvement of students occurred with interaction with the IWB and with the other classroom activities. The increased involvement was mainly due to an increase in interest in the classroom activities spurred by the use of an IWB.

\section{Quantitative Analysis}

The quantitative analysis of the $t$ - test failed to produce any statistical significance data at the .05 level. Additional quantitative procedures had the same results. However the failure to find statistical significance data is not uncommon with action research due to the small sample size. During the statistical analysis two findings that should be noted were discovered. First, the largest gain in test scores transpired during the first week of using an IWB. This finding is important because the first week would be when the students would be most susceptible to the variable. The gain however failed to reach statistical significance. This failure could be due to the small sample size of this action research. The second trend that additionally points to the positive effects of the use of an IWB is the difference in test scores between test 2 and test 3 . Class $\mathrm{A}$ displayed a drop of 6.38 between test 3 and test 2 . This is the same time period when the use of the IWB was taken away. The fact the biggest gain resulted initially after the IWB was employed and the largest drop occurred directly after the IWB was taken away, points to the importance the use of an IWB had on the students' assessment scores. As stated earlier given a larger sample size, these trends could prove to be statistically significant at the .05 level. The low sample of 34 did not allow for the trends to show statistical significance. 


\section{Biblical Integration}

When looking at technology and the role that technology has in education from a biblical view it is easy to apply the principle of stewardship. We are called by God to be stewards of the earth. We are to take care of the earth and the creatures of the earth. Not only are we called to take care of the earth but to do that the best way we can. In 1 Corinthians, Paul points out to us we should do our best. Paul states "Run the race as to win the prize." Additionally we are, "To do all things for the glory of God." We are to do the best we can. Therefore if using an IWB improves education we should use it. However as Christians we know that the world is fallen and sin affects everything and we must use caution. Since Christ has made us all uniquely special we want to individualize, yet not make this a selfish or self-serving individualism. Yet a caveat I think should be considered is just because students enjoy the IWB does not make it a bad thing, yet care has to be taken to see that abuse that create self-centeredness are avoided. My conclusions are that the potential educational benefits of the IWB make the IWB something that educators should use.

\section{Relation of the results to Literature}

Analyzing results in light of current literature showed this study to be congruent with findings from other studies. One area of similar findings is with increased engagement and increased interest levels, as noted in Knowlton (2008), which found improved student engagement. Similarly Wall, Higgins \& Smith's (2005) findings mentioned motivation and the IWB being fun as their most positive response. This same perception was found in the current study. Increased engagement and interest was also 
noted by the Apple lap top study (2007). Slay, Sieborger and Hudgkinson (2007) also had positive findings relating to the increased interest levels of students.

The finding of increased student achievement has been mixed in other studies. Susskind (2008) found no achievement differences. Apperson et. al. (2006) while studying PowerPoint found that there was no impact on the final grades. Szabo \& Hastings (2000) also found PowerPoint to have no difference in terms of final grades. However Marzano (2009) found achievement gains by using an IWB. Additional studies conducted by the IWB companies also have found achievement gains. During the studies of Susskind (2008) and Apperson et.al. (2006) other educational benefits, besides achievement gains, were made mainly in the area of self-efficiency. Both studies noted students valuing the technology because the students believed the technology made school work easier. In this study students made similar comments about believing the use of an IWB made work easier.

Another finding that relates to the current literature is the increased speed at which class work is completed. Smith, Hardman, \& Higgins (2005) found quicker lesson pace while students answered more questions. The mentioning of a quicker classroom pace was positively noted by the students in this study. No students mentioned class being too quick or not being able to keep up. As the class moved at a faster pace, the manner in which class was taught also had a slight shift. As noted in both McNabb \& Hassel (2000) and in Smith, Hardman, \& Higgins (2006) the IWB causes classrooms to tend to be more whole group. The whole group style was positively viewed by most students. One student commented on feeling like they were on a team with everyone working together to get their work done. 
In addition to finding similar positives, similar drawbacks and improvements to the use of an IWB were also noted. The main limitations and drawbacks noted in this study are similar to those found in the current literature. The main limitation with technology is basically errors which occur due to either a lack of technical support, or a lack of technical training. Students of this study noted flaws dealing with and related to the IWB as a result of either a technical error such as slow loading time, broken hyperlinks, or the computer freezing up. Those similar technical difficulties had been noted in studies by Hall \& Higgins (2005) and in Hicks, Doolittle, \& Lee (2004). The other limitations of the IWB were results of the lack of technical or computer skills by the teacher. Lack of teacher computer skills have been noted as a major drawback in many studies including Slay, Sieborger, \& Hodgkinson-Williams which noted that lack of ICT skills by teachers was the biggest disadvantage to using technology. McNabb \& Hassel (2000) also noted a lack of teacher computer skills as a hurdle for using technology in the classroom. Reedy (2008) also noted that the lack of training resulted in teachers using IWBs in primitive ways and not using the IWB to their full potential.

Improvements as to the use of the IWB additionally mirrored the current research as well. Yanik \& Porter (2008) found that students wanted to work with computers more. Hall \& Higgins (2005) also noted that students had a desire to use the IWB more. These two studies echo the opinions of the students of this study. Students of this study mentioned using the IWB more would be the number one way that the use of an IWB could be improved.

In general, the findings were of a positive view about the IWB are consistent with the current research. The positive effects on students' engagement, increased perception 
of learning, and other classroom benefits, such as increased speed and organization, are on par with the current literature. Additionally the limitations and areas of improvement are also in line with the current literature. The academic gain is consistent with those studies that focused on academic gain. However the existence of academic gain has not been found at the rate that the positive view of technology has been shown. Strengths of the study

This project implicated the use of action research in a mixed quantitative and qualitative design which allows for the results to be generalized to other similar classroom settings. The mixed approach helped to insure the reliability of the findings. The quantitative and qualitative aspects of the study work congruently to insure that each type of approach could support the other. The qualitative aspects focused on the students perceptions of technology. After finding a positive view of the IWB, the quantitative aspect insured a measurement of academic gain. By employing both approaches I was able to determine that not only did students positively view the IWB but that the IWB did have a positive affect on student achievement even though not at a statistical significance.

The finding of both these facts is a strength that can be generalized to others in the field of education. Educators value instructional techniques that students enjoy. Educators also value instructional techniques that increase student achievement. At the highest value is those techniques that can do both.

The within subject design and counterbalancing of order allowed for each class to serve as its own control. Because of the length of the study each class was able to clearly see the difference between the IWB and overhead. In addition, by using the same 
textbook manufactured assessments, the achievement gain could be clearly measured, by employing the same weekly assessments allowed for the IWB to be the only variable in the research. Additionally other classroom factors such as class time, class size, and classroom assignments, were kept constant.

The data collection involved collecting qualitative data in two different ways. Journals and interviews were used to collect the qualitative data, while four weekly language arts tests were used to collect the quantitative data. The collection of qualitative data from two sources allowed for saturation as did the collection of quantitative data from the four weekly tests.

\section{Limitations of the study}

The use of interviews and journals resulted in some students offering more description and detail in their responses than other students. Another limitation was that due to the fact the school year had already begun, random selection was not possible. The classes were set from the start of the year. Another consideration should be that of the novice skill of the teacher concerning the use of an IWB. At the start of this study I had approximately one month of experience with this particular IWB. However from my undergraduate work I had been exposed to a different IWB. Additionally this school year was the first time the students in my school were exposed to IWBs. Additionally as often is the case with action research, the low sample size hindered the results' ability to show any statistically significant data. Other limitation to be considered was the assessments were given in a paper pencil style. The IWB was used only for instruction and not for assessment. An additional limitation would be the background of the student's regarding their previous exposure to technology and the use of technology as a teaching tool. 
Suggestions for future Research

For additional research, the study should be expanded both in number of participants and to other subject areas such as math and science. Additionally, the study should take into account a wider range of students' ages. A study of how primary, middle school, and high school students view the IWB would benefit educators, particularly by discovering the nuances associated with each age level. Furthermore the exact practices of the IWB that promotes student achievement need to be discovered. Currently the IWB has a wide range of acceptable practices. The practices need to be narrowed and cultivated, to allow only the most fruitful practices to continue to exist. 
Appendix A

Interview Questions

1. What do you like about the IWB and what do you like about the overhead and why?

2. What do you not like about the IWB and what do you not like about the overhead and why?

3. In what ways do you think the IWB helps you learn compared to the overhead?

4. Did the IWB make you more or less interested in class? How or why?

5. Can you think of a specific time when the IWB changed your interest level? Explain the activity when this interest level changed.

6. Do you prefer the overhead or the IWB?

7. Think about the topics we have learned this year, (homographs, fact and opinion, sequencing, persuasion, and context clues) explain how the IWB helped you understand one of those topics.

8. What do you not like about the IWB? Is it distracting in anyway?

9. What problems have you seen with the IWB?

10. Have you been able to use the IWB, and if so would you say it is hard or easy to use, why?

11. What is one thing that I could do with the IWB to make class more interesting?

12. What makes a teacher "good" at using the IWB? Explain.

13. What do you think of the IWB overall? What is your opinion of the IWB? 
Appendix B

Parental Consent form

January 15,2010

Dear Parents/Guardians,

Paint Valley Elementary has purchased interactive whiteboards for each of the elementary classrooms. These interactive whiteboards are called Smart Boards. They have several interesting features that we feel will benefit the education of the students at Paint Valley. I am currently in the process of trying to complete my Masters in Education, and has part of my Masters program I am going to be conducting research on the students' perceptions of the Smart board. At this time I am requesting permission to interview your student about their perception of the Smart board. Participation in this study will have no effect either positive or negative on your student's grade. Thank you for your help. If you have any questions, please feel free to email me at any time.

Sincerely,

Mr. Burke

I give permission for my student to be interviewed regarding his/her opinion of the Smart board. I understand confidentiality will be maintained.

Student's name: Date:

Parent/Guardian signature: 


\section{Sample Journal Entry}

$1-27-2010$

1. If the IWB was used today, in what ways was it helpful to you?

If the IWB was not used, in what ways were the other technologies (overhead, dry-erase board, television) helpful to you?

It was helpfill so I could see answers for my guided notes.

2. With respect to technology, what did you not like or what was not helpful about today's class?

Mr. Burke's hand writing was a little sloppy.

3. In what ways could technology have been better used for today's class?

If we could of used the IWB more. 


\section{REFERENCES}

Apperson, J. M., Laws, E. L., \& Scepansky, J. A. (2006). The Impact of Presentation Graphics on Students' Experience in the Classroom. Computers and Education $47(1), 116-126$.

Apperson, J. M., Laws, E. L., \& Scepansky, J. A. (2008). An Assessment of Student

Preferences for PowerPoint Presentation Structure in Undergraduate Courses. Computers \& Education, 50(1), 148-153.

Apple Education. (2009). The Mac is perfect for learning. Retrieved December 22, 2009, from www.apple.com/education/teachers-prefessors/built-for-education.html

Boon, R., Burke, M., Fore, C., Hagen-Burke, S., (2006). Improving Student Content Knowledge in Inclusive Social Studies Classrooms Using Technology-Based Cognitive Organizers: A Systematic Replication. Learning Disabilities: A Contemporary Journal, 4(1), 1-17.

Branzburg, J. (2006). Use an Interactive Whiteboard: Get a Handle on How This Technology Can Spice up the Classroom. Technology \& Learning, 26(6), 31.

Brown, D., \& Warschauer, M. (2006). From the University to the Elementary Classroom: Students' Experiences in Learning to Integrate Technology in Instruction. Journal of Technology and Teacher Education, 14(3), 599-621.

Cheng, G. (2009). Using game making pedagogy to facilitate student learning of interactive multimedia. Australasian Journal of Educational technology 25(2), 204-220. 
Clark, K. F., Hosticka, A., Schriver, M., Bedell, J., (2002). Computer Based Virtual Field Trips. (ERIC Document Reproduction Service No. ED 476 987).

Constructivist Theory. (2010). Retrieved July 20, 2010, from http://tip.psychology.org/bruner.html

Dede, C. (1997). Rethinking How To Invest in Technology. Educational Leadership, no. $3,12-16$.

Dede, C. (1983). The Likely Evolution of Computer Use in Schools. Educational Leadership, 4l(1), 22-24.

DenBeste, M. (2003). PowerPoint, Technology and the Web: More than just an Overhead Projector for the New Century? The History Teacher 36(4), 491-504.

Driscoll, M. P. (2002). How people learn (and what technology might have to do with it. Syracuse, NY: ERIC Clearinghouse on Information and Technology. (ERIC Document Reproduction Service No. ED470032)

Dwyer, D. C., Ringstaff, C., Sandholtz, J. H., (1991). Changes in Teacher's Beliefs and Practices in Technology-Rich Classrooms. Educational Leadership, 45-52.

Edwards, J., Hartnell, M., Martin, R., (2002). Interactive whiteboards: some lessons from the classroom. Micromath 18(2), 30-33.

Frey, B. A., \& Birnbaum, D.J. (2002). Learners'Perceptions on the Value of PowerPoint in Lectures. (ERIC Document Reproduction Service No. ED467192) 
Glover, D., \& Miller, D. (2007). Leading changed classroom culture- the impact of interactive whiteboards. British Educational Leadership, 21(3), 21-24.

Gustafson, K. (2004). The Impact of Technologies on Learning. Planning for Higher Education, 32(2), 73-43.

Handal, B., \& Herrington, A. (2004). On Being Dependent or Independent in Computer Based Learning Environments. E-Journal of Instructional Science and Technology, $7(2)$

Honey, M. (2001). Retrieved July 20, 2010, from cct.edc.org/admin/publications/speeches/testimony_lhe01.pdf

Honey, M., Culp, K. M., \& Carrigg, F. (2000). Perspectives on Technology and Education Research: Lessons from the Past and Present. Journal of Educational Computing Research, 23(1), 5-14.

Hooppingarner, D. (2009). Best Practices in Technology and Language Teaching. Education and Pedagogy. Retrieved July 20, 2010, from http://www.blackwellcompass.com/subject/linguistics/article_view?article_id=lnco_article

Internet Access in U.S. Public Schools and Classrooms: 1994- 2001. Retrieved December 15, 2009, from http://nces.ed.gov/pubs2002/Internet/4.asp

Introduction- What is ICT? (2006). Retrieved December 22, 2009, from http://www.tutor2u.net/business/ict/intro what is ict.htm 
Johnson, B., \& Christensen, L. (2004). Educational research: Quantitative, qualitative, and mixed approaches. Boston: Pearson.

Kelly, R. (2006). Smart Classroom. Campus Technology, 20(4), 13-16.

Kennewell, S., \& Beauchamp, G. (2007). The features of interactive whiteboards and their influence on learning. Learning, Media and Technology, 32(3), 227-241.

Kent, P. (2006). Using Interactive whiteboards to Enhance Mathematics Teaching. Australian Primary Mathematics Classroom, 11(2), 23-26.

Kirkwood, A., \& Price, L. (2005). Learners and learning in the twenty-first century: What do we know about student's attitudes towards and experiences of information and communication technologies that will help us design courses? Studies in Higher Education, 30(3), 257-274

Knowlton, N. (2009). Engagement and Assessment- A student's Perspective. Retrieved November 18, 2009, from http://www2.smarttech.com/

Knowlton, N. (2009). SMART products increase student engagement in U.S. classrooms. Retrieved November 20, 2009, from http://www2.smarttech.com/

Knowlton, N. (2009). Two U.S. schools improve test scores with SMART products. . Retrieved November 20, 2009, from http://www2.smarttech.com/

Knowlton, N. (2007). Interactive Whiteboard Research Shows. Retrieved November 18, 2009, from http://www2.smarttech.com/ 
Lee, J.K. (2002). Digital History in the History/Social Studies Classroom. The History Teacher, 35(4), 503-517.

Leu, D. J. (2002). Internet Workshop: Making Time for Literacy. Reading Teacher, $55(5), 466-472$.

Leu, D.J., Jr., \& Leu, D.D. (1999). Teaching with the internet: Lessons form thw Classroom (1999Ed.). Norwood, Massachusetts: Christopher-Gordon Publishers, Inc.

Martin, S. (2007). Interactive Whiteboards and talking books: a new approach to teaching children to write? Literacy, 4l(1), 26-34.

McNabb, M L., \& Hassel, B. (2000). Literacy Learning on the Net: An Exploratory Study. North Central Regional Educational Laboratory (ERIC Document Reproduction Service No. ED450344)

Miller, N. C., Thompson, N.L., \& Franz, D.P. (2009). Proactive Strategies to Safeguard Young Adolescents in th Cyberage. Middle School Journal, 41(1), 28-34.

Miners, Z. (2009). Classroom Technology Integration. District Administration, 45(4), 3538.

Mounce, A.B. (2008). Teaching Content with Interactive Whiteboards. Journal of Specail Education Technology, 32(1), 54-58. 
Nichols, J. (2007). Technology Integration Model for Teachers. Retrieved November 18, 2009, form http://www.teach-nology.com/Articles/integrate/

PowerPoint In the classroom. (2007). Retrieved November 18, 2009, from http://www.teach-nology.com/Articles/powerpoint/

Pratt, D., \& Davison, I. (2003). Interactive Whiteboards and the Construction of Definitions for the Kite. International Group for the Psychology of Mathematics Education Conference (ERIC Document Reproduction Service No. ED501064)

Reedy, G.B. (2008). PowerPoint, interactive whiteboards, and the visual culture of technology in schools. Technology, Pedagogy and Education, 17, 143-162.

Robertson, S., \& Hudgins, M. (2008). Technology Not Being Used Effectively In Schools, Teachers Need Professional Development and Support to Implement School Technology. Retrieved November 18, 2009, from http://www.nea.org/bare/print.html?content=/bare10908.htm

Sadler, (2002). The concept of Non-Liner PowerPoint. Retrieved July 20, 2010, from http://wwwl.harlingen.isd.tenet.edu/pdf/nonlinear.pdf

Shenton, A. \& Pagett, L. (2007). From 'bored' to screen: the use of the interactive whiteboard for literacy in six primary classrooms in England. Literacy, 41, 129-136.

Shorr, P. W. (2006). The New Digital Wave [Dive in! Whiteboards are quickly changing how we teach.] Instructor, 24-27. 
Simpson, C. (2005). TEACHing and the Internet. Library Media Connection, 24(1), 2325.

Slay, H., Sieborger, I., \& Hodgkinson-Williams, C. (2007). Interactive whiteboards: Real beauty or just "lipstick"? Computers \& Education, 51, 1321-1341.

SMART Technologies, Interactive Whiteboards and Learning: Improving student learning outcomes and streamlining lesson planning. (2006). Retrieved November 23, 2009, from http://www.smarttech.com

Smith, F., Hardman, F., \& Higgins, S. (2006). The impact of interactive Whiteboards on teacher-pupil interaction in the National Literacy and Numeracy Strategies. British Educational Research Journal, 32(3), 443-457.

Starkman, N. (2006). The Wonders of Interactive Whiteboards. T.H.E. journal, 33(J0), 36,38 .

Susskind, J. E., (2008). Limits of PowerPoint's Power: Enhancing students' self-efficacy and attitudes but not their behavior. Computers \& Education, 50, 1228-1239.

Szabo, A., \& Hastings, N. (2000). Using IT in the undergraduate classroom: should we replace the blackboard with PowerPoint? Computers \& Education, 35, 175-187.

Talbot County Public Schools: One to One Laptop Initiative. Year 2: 2006-2007 Evaluation. Retrieved December 23, 2009, from http://images.apple.com/education/docs/leaders/Apple-JohnsHopkinsResearch.pdf 
Taylor, J.A., \& Duran, M. (2006). Teaching Social Studies with Technology: New Research on Collaborative Approaches. History Teacher, no.1,9-25.

Vail, K. (2003). School technology grows up. American School Board Journal, 190(9), 34-37.

Wall, K., Higgins, S., \& Smith, H. (2005). The visual helps me understand the complicated things': pupil views of teaching and learning with interactive whiteboards. British Journal of Educational Technonlogy, 36(5), 851-867.

White, N., Ringstaff, C., \& Kelley, L. (2002). Getting the most from Technology in Schools. Knowledge Brief. WestEd. (ERIC Document Reproduction Service No. ED471137)

Wu, Z., \& Glaser, E. (2004). Software for the Synergistic Integration of Science with ICT Education. Journal of Information Technology Education, 3, 325-339.

Yanik, H. B., \& Porter, W. (2009). Promoting Effective Use of Technology through Teacher-Researcher Collaboration. International Journal for Technology in Mathematics Education, 16(1), 3-10. 
